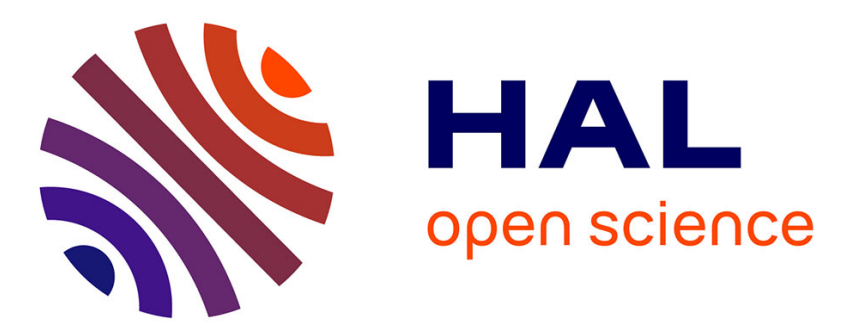

\title{
Evidence for radial anisotropy in the lower crust of the Apennines from Bayesian ambient noise tomography in Europe
}

Chloé Alder, Eric Debayle, Thomas Bodin, Anne Paul, Laurent Stehly, Helle Pedersen

\section{To cite this version:}

Chloé Alder, Eric Debayle, Thomas Bodin, Anne Paul, Laurent Stehly, et al.. Evidence for radial anisotropy in the lower crust of the Apennines from Bayesian ambient noise tomography in Europe. Geophysical Journal International, 2021, 226, pp.941-967. 10.1093/gji/ggab066 . hal-03196210

\section{HAL Id: hal-03196210 https://hal.science/hal-03196210}

Submitted on 12 Apr 2021

HAL is a multi-disciplinary open access archive for the deposit and dissemination of scientific research documents, whether they are published or not. The documents may come from teaching and research institutions in France or abroad, or from public or private research centers.
L'archive ouverte pluridisciplinaire HAL, est destinée au dépôt et à la diffusion de documents scientifiques de niveau recherche, publiés ou non, émanant des établissements d'enseignement et de recherche français ou étrangers, des laboratoires publics ou privés. 


\section{Evidence for radial anisotropy in the lower crust of}

\section{the Apennines from Bayesian ambient noise}

\section{tomography in Europe}

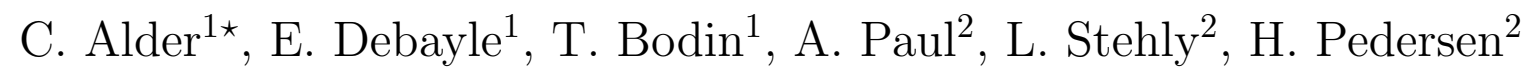
and the AlpArray Working Group ${ }^{\dagger}$

1 Univ Lyon, ENSL, Univ Lyon 1, CNRS, LGL-TPE, F-69007 Lyon, France

2 Univ. Grenoble Alpes, Univ. Savoie Mont Blanc, CNRS, IRD, IFSTTAR, ISTerre, 38000 Grenoble, France

SUMMARY

Probing seismic anisotropy of the lithosphere provides valuable clues on the fabric of rocks. We present a 3-D probabilistic model of shear wave velocity and radial anisotropy of the crust and uppermost mantle of Europe, focusing on the mountain belts of the Alps and Apennines, The model is built from Love and Rayleigh dispersion curves in the period range 5 to 149 s. Data are extracted from seismic ambient noise recorded at 1521 broadband stations, including the AlpArray network. The dispersion curves are first combined in a linearised least squares inversion to obtain 2-D maps of group yelocity at each period. Love and Rayleigh maps are then jointly inverted at depth for shear wave velocity and radial anisotropy using a Bayesian Monte-Carlo scheme that accounts for the trade-off between radial anisotropy and horizontal layering. The isotropic part of our model is consistent with previous studies. However, our anisotropy maps differ from previous large scale studies that 2 suggested the presence of significant radial anisotropy everywhere in the European crust and shallow upper mantle. We observe instead that radial anisotropy is mostly 
localized beneath the Apennines while most of the remaining European crust and shallow upper mantle is isotropic. We attribute this difference to trade-offs between radial anisotropy and thin (hectometric) layering in previous studies based on leastsquares inversions and long period data (>30 s). In contrast, our approach involves a massive dataset of short period measurements and a Bayesian inversion that accounts for thin layering. The positive radial anisotropy $\left(V_{S H}>V_{S V}\right)$ observed in the lower crust of the Apennines cannot result from thin layering. We rather attribute it to ductile horizontal flow in response to the recent and present-day extension in the region.

Key words: Seismic anisotropy; Seismic noise; Surface waves and free oscillations; Seismic tomography; Europe

\section{INTRODUCTION}

The convergence between the large Eurasian and African plates, which started in the early Cretaceous, is responsible for the creation of several orogens in the Mediterranean region such as the Alps, Carpathians, Apennines and Dinarides (e.g. Handy et al. 2010) (Figure 1). Several microplates were involved during the stages of subduction and collision. Among them, the Adriatic microplate (or Adria) played a key role in the current geodynamic structure of the Western and Central Mediterranean region and its collisional mountain belts. Adria is the upper plate of continental subduction in the Western and Central Alps, while it is the lower plate in the Apenninic and Dinaric subductions (e.g. Wortel \& Spakman 2000; Lippitsch et al. 2003; Spakman \& Wortel 2004). The question of which plate is subducting underneath the other in the Eastern Alps is still unresolved (e.g. Lippitsch et al. 2003; Koulakov et al. 2009; Mitterbauer et al. 2011; Zhao et al. 2016a). This complex tectonic setting is associated with high deformation in the crust (e.g. Nocquet \& Calais 2004), switches in subduction polarity in the Alps-Apenninés transition (Vignaroli et al. 2008; Zhao et al. 2016a) and Eastern Alps (Lippitsch et al. 2003) and complicated geometry of slabs in the mantle (e.g. Vignaroli et al. 2008; Faccenna et al. 2014). In addition, Adria plays an important part in the seismic hazard of the region as illustrated by the high concentration of earthquakes in the Apennines, Eastern

* E-mail address: chloe.alder@ens-lyon.org

$\uparrow$ AlpArray website: www.alparray.ethz.ch/en/home/ 


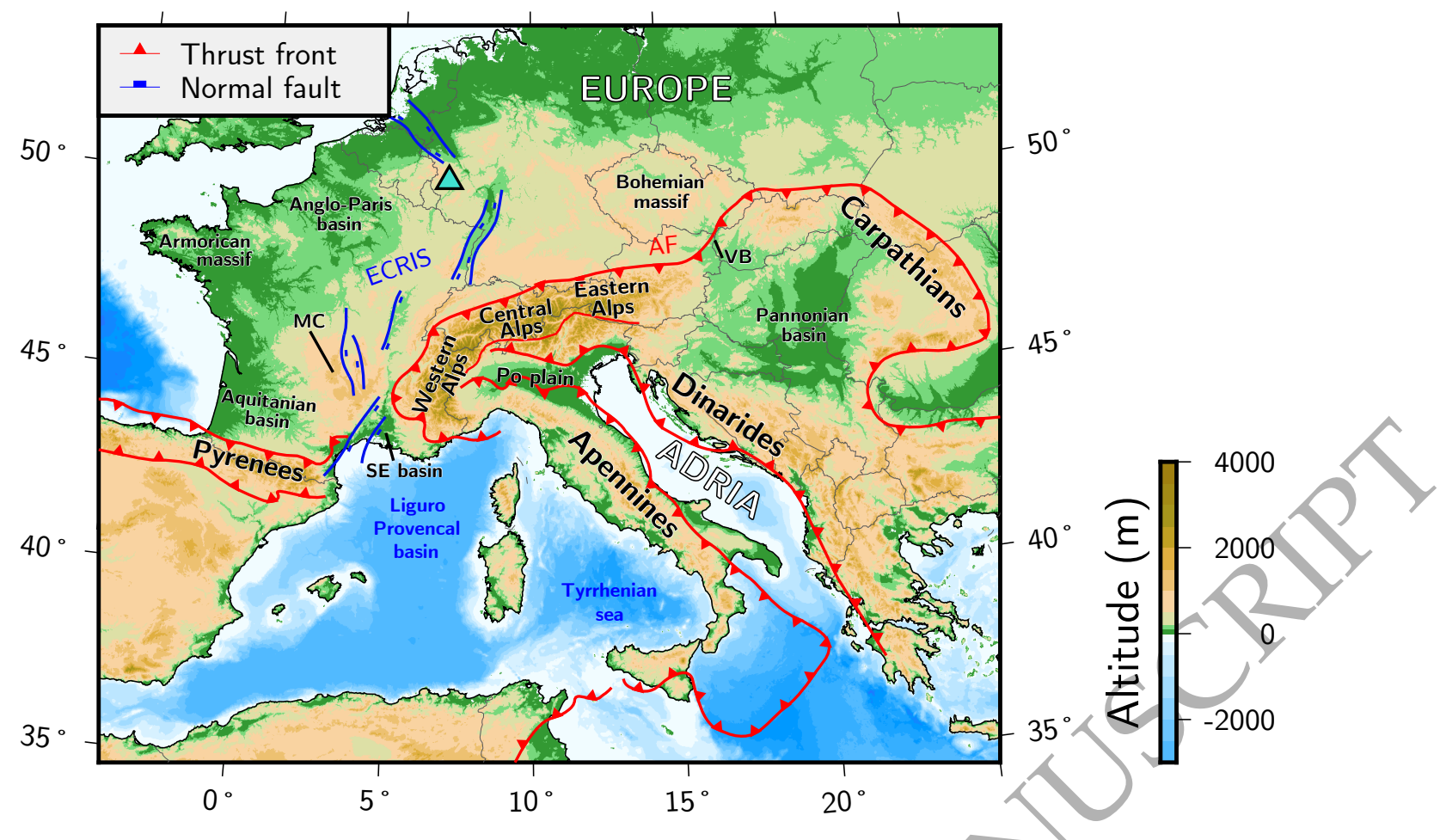

Figure 1. Topographic map of the study area and main geological features. MC: Massif Central; VB: Vienna basin; SE basin: Southeast basin; ECRIS: European Cenozoic rift system; AF: Alpine front. Turquoise triangle: Eifel hotspot.

Alps and Dinarides due to the convergence of Adria and Europe, which is still active in those areas.

In such a complex setting, seismic imaging is a tool of decisive importance to provide constraints on the lithospheric structure and fabric of crustal and mantle rocks that are necessary to build geodynamical models of the region. Teleseismic travel-time P-wave tomography of the mantle has allowed to map subducting slabs at large scale beneath Europe down to the transition zone and to observe slab detachments (Spakman et al. 1993; Lucente et al. 1999; Wortel \& Spakman 2000; Piromallo \& Morelli 2003). However, teleseismic travel-time tomography has a poor vertical resolution in the upper mantle because of steeply incident rays. Alternatively, long period surface wave tomography has been used to produce regional 3-D models of shear wave velocity beneath Europe (Boschi et al. 2004; Pasyanos 2005; Weidle \& Maupin 2008; Schivardi \& Morelli 2011). Nevertheless, all these tomographic models are based on earthquake sources, so their spatial resolution is limited by the ray coverage.

In order to increase resolution, Zhu et al. $(2012,2015)$ proposed an adjoint approach to simultaneously invert body and surface waveforms. One advantage of inverting full waveforms is to mitigate the issue of ray coverage, as waveforms contain scattering and a broader sensitivity 
to structure (Fichtner et al. 2010; Lekić \& Romanowicz 2011). They found many smaller-scale structures such as more detailed slab geometries, mantle upwellings and lithospheric delaminations. However, the resolution in full-waveform inversion is limited by the frequency content of inverted waveforms. As a result, the studies from Zhu et al. $(2012,2015)$ are focused on the mantle structure and do not provide detailed information in the crust.

Ambient noise tomography has proven to be a reliable technique to improve both data coverage and resolution at crustal depth and at continental scale in Europe (Stehly et al. 2009; Verbeke et al. 2012; Molinari et al. 2015; Kästle et al. 2016, 2018; Lu et al. 2018, 2020; Zhao et al. 2020). In the Alps and Apennines, Molinari et al. (2015) invert simultaneously Rayleigh wave group and phase velocities between 5 and $37 \mathrm{~s}$ to retrieve the distribution of 3 -D shear velocity in the crust. Lu et al. (2018) invert Rayleigh group velocities in a broader period range (5-150 s) to reconstruct the 3 -D shear velocity structure in the crust and the uppermost mantle beneath Europe. Kästle et al. (2018) combine ambient noise and earthquake data to map shear velocities down to $220 \mathrm{~km}$ depth.

These ambient noise tomographic models agree on the first-order isotropic structures and show a good agreement with both active and passive seismic studies. As opposed to teleseismic studies, their level of resolution (a few tens of $\mathrm{km}$ laterally and a few $\mathrm{km}$ vertically) allows to map crustal heterogeneities and shallow structures such as sedimentary basins. However, they do not account for seismic anisotropy. This is a clear limitation, as including azimuthal or radial anisotropy helps to map the fabric of crustal and mantle rocks, whose knowledge is of great interest in regions that have undergone high strain during their tectonic history.

Our knowledge of azimuthal anisotropy beneath the Alps and Italy mostly comes from SKS splitting studies. Fast velocity directions are generally parallel to the mountain chain in the Western and Central Alps (Barruol et al. 2004; Lucente et al. 2006; Barruol et al. 2011; Salimbeni et al. 2018), the Eastern Alps (Bokelmann et al. 2013; Qorbani et al. 2015) and the Apennines (Palano 2015). A few studies have addressed azimuthal anisotropy in Europe from surface wave analysis but they are usually at local scale (e.g. Fry et al. 2010; Schippkus et al. 2020) or use periods that do not resolve crustal structure well (e.g. Nita et al. 2016). Radial anisotropy beneath Europe is mostly known from very large scale or global surface wave studies where the crust is not resolved (Kustowski et al. 2008; Weidle \& Maupin 2008; Boschi et al. 2009; Zhu et al. 2015; Schivardi \& Morelli 2011). All these studies are constructed from long period observations, where the crust is not inverted for but fixed from a reference model such as for example CRUST1.0 (Laske et al. 2013). However, although details within the crust cannot be resolved by long-period seismic waves, errors in the 
reference crustal model may bias images of the upper mantle. Indeed, trade-offs exist between heterogeneities in the crust (e.g. Moho topography) and anisotropy in the mantle (Bozdağ \& Trampert 2008; Panning et al. 2010; Chang \& Ferreira 2017). In particular, apparent positive radial anisotropy $\left(V_{S H}>V_{S V}\right)$ in long wavelength tomographic models may be induced by horizontal layering (e.g. Backus 1962; Bodin et al. 2015; Alder et al. 2017). This may be an important effect in Western Europe, as thin (hectometric) layering of the lower crust has been inferred from ubiquitous observations in deep seismic reflection profiles of the Variscan crust (Paul \& Nicollin 1989; Singh \& McKenzie 1993; Rey 1993). In the long period studies cited above, radial anisotropy is ubiquitous as it may improve data fit without the need for modelling isotropic small-scale structures. In this context, radial anisotropy cannot reliably be used to interpret models derived from long-period surface waves in terms of structural fabric, i.e. lattice preferred orientation (LPO) of anisotropic minerals, resulting from deformation. At shorter periods, Stehly et al. (2009); Kästle et al. (2018) measured both Rayleigh and Love dispersion but they did not invert them jointly for radial anisotropy at depth.

The aim of this study is to build the first 3-D model of radial anisotropy for the crust and uppermost mantle beneath Europe, in particular beneath the Alps and Apennines. We use a massive ambient noise surface wave dataset analysed in a broad frequency range (5 to $149 \mathrm{~s}$ ). Taking advantage of the AlpArray temporary network (Hetényi et al. 2018) and surrounding permanent networks, we assemble a new large dataset of ambient noise Rayleigh and Love group velocities recorded at more than 700,000 station pairs. Two reasons led us to use group velocity instead of phase velocity, First, group velocities are easier to extract from noise correlation than phase velocities. Their estimations are therefore usually more robust and have proven to be a reliable choice in ambient noise tomography (e.g. Shapiro \& Campillo 2004; Shapiro et al. 2005; Yang et al. 2007; Stehly et al. 2009; Lu et al. 2018). In addition, group velocities are sensitive to shallower structure than phase velocities for the same period range (e.g. Forsyth 1975). Our goal is to focus on the Vs structure of Europe from crust to uppermost mantle. Given the period range available, the use of fundamental-mode group velocities is then justified by the targeted depth range.

A standard 2-D linear least-squares tomography is first performed at each period on Rayleigh and Love dispersion data. In a second step, Rayleigh and Love dispersion data are jointly inverted at each geographical location for a 1-D depth profile of shear wave velocity and radial anisotropy. This 1-D inversion is done within the transdimensional hierarchical Bayesian framework of Bodin et al. (2012b, 2016); Yuan \& Bodin (2018), where the trade-off between horizontal layering and radial anisotropy is accounted for. That is, the number of 
layers in the inverted 1-D models is determined by the data themselves and anisotropy is added in each layer only if required by the data. Finally, all the 1-D models are assembled to create a regional 3-D probabilistic anisotropic model.

This study is focused on radial anisotropy. Such a goal requires an identical data coverage for Love and Rayleigh waves to perform a joint inversion of Love and Rayleigh group velocity maps with identical resolutions. Since Love waves observed on the correlations of horizontal components (transverse-transverse) have a lower signal-to-noise ratio than Rayleigh waves observed on vertical-vertical correlations, we have to reject a large part of the Rayleigh measurements that would have been used for imaging isotropic structures. We therefore emphasize that the goal of this study is not to improve the resolution of isotropic structures compared to previous high-resolution ambient noise models of the region (e.g. Lu et al. 2018; Kästle et al. 2018) but instead to image radial anisotropy across Europe in a way that is not biased by different data coverage of Rayleigh and Love waves.

The novelty of our approach is to combine a unique and massive dataset of Rayleigh and Love wave measurements over a broad period range with a Bayesian inversion. This Bayesian approach allows to sample the ensemble of possible anisotropic layered models, where each layer can be either isotropic or anisotropic. In this way, anisotropy is not imposed at the outset but is introduced only if required by the data. This data-driven procedure prevents us from getting an anisotropic signal everywhere in the model, as it is the case in previous studies in Europe. Indeed, we show that radial anisotropy is overall not pervasive in the crust and uppermost mantle. Radial anisotropy is only unambiguously present in specific areas, mainly in the lower crust of the Apennines, where it could be related to the recent and present-day extensive deformation of the Adriatic plate.

\section{SURFACE WAVE DATASET}

\subsection{Group velocity measurements from ambient noise correlations}

We use a dataset of group velocity dispersion curves in the period range 5-149 s for both Rayleigh and Love waves. The group velocity measurements are obtained from ambient noise correlation following an approach similar to the one described in Lu et al. (2018). We summarize here its main steps and refer to Lu et al. (2018) for a more detailed description.

Dispersion measurements are obtained from cross-correlations of ambient seismic noise recorded on horizontal and vertical components at 1521 broadband European stations. The locations of receivers, which belong to the AlpArray temporary experiment (Hetényi et al. 


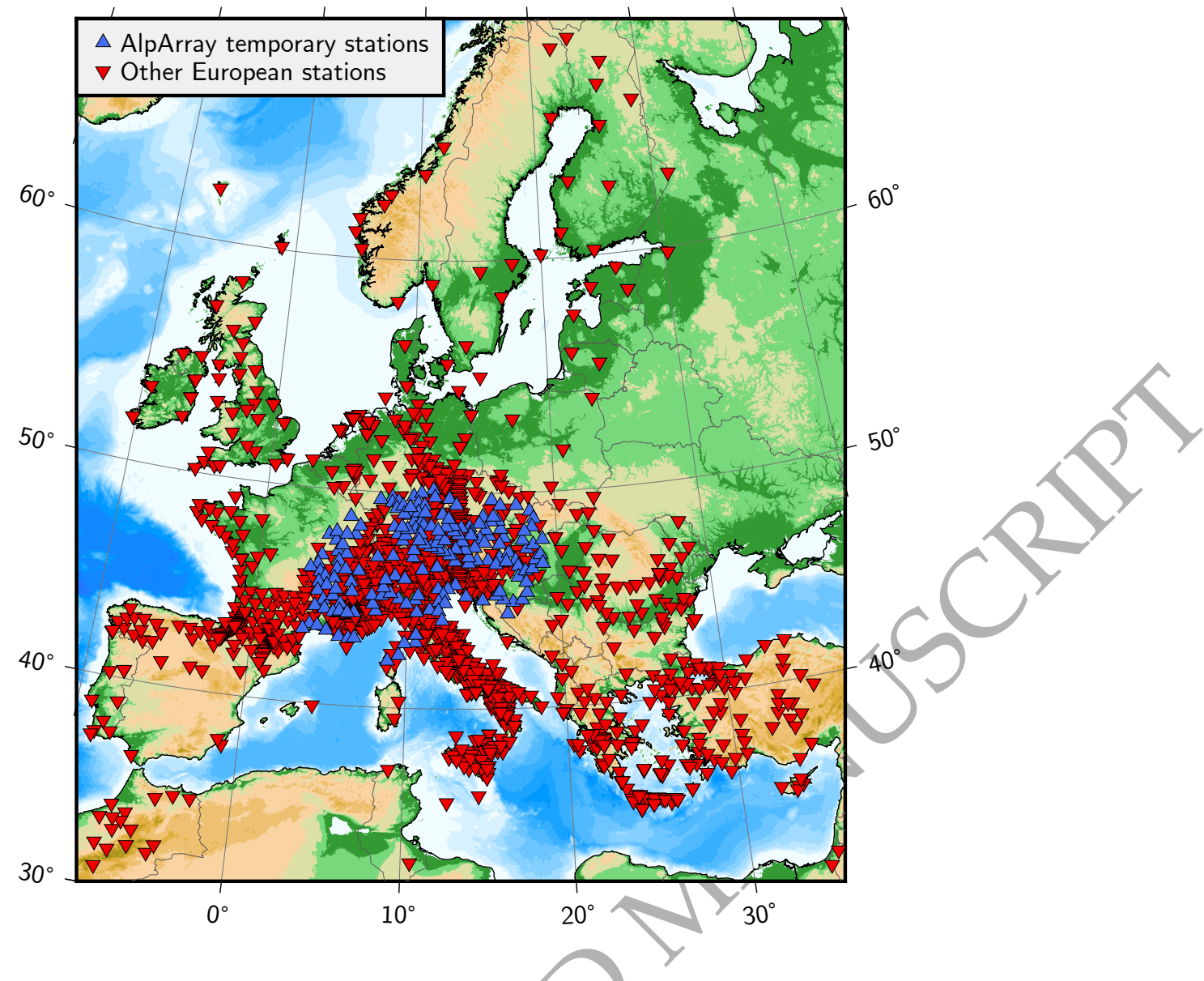

Figure 2. Map of the 1521 broadband stations used in this study. Blue triangles represent receivers belonging to the AlpArray temporary seismic network (Hetényi et al. 2018). Red triangles correspond to stations from other temporary and permanent networks in and around Europe.

2018) and other European permanent and temporary seismic networks, are shown in Figure 2. Continuous seismic noise signals recorded between 2010 and 2016 are correlated in the period range 30-149 s for all stations that were in operation in that time period. Noise recordings from 2016 to 2017 are correlated in the period range 5-100 s for all available permanent and temporary stationsincluding AlpArray. As in Lu et al. (2018), cross correlations are computed by segments of 4 hours before being stacked over the whole record duration. Group velocity dispersion curves for the fundamental mode of Love and Rayleigh waves are derived from the stacked correlations using a time-frequency analysis (Dziewonski et al. 1969; Herrmann 1973; Levshin et al. 1989). Rayleigh and Love wave dispersion curves are respectively estimated from the ZZ (vertical-vertical) and TT (transverse-transverse) correlations. 


\subsection{Measurements selection}

At each period, we only select the best quality Rayleigh and Love group velocity measurements. The selection follows classical steps used in ambient noise tomography (e.g. Lu et al. 2018). They are based on signal-to-noise ratio, symmetry of the stacked correlations to minimize the error on group velocity estimations due to the directionality of noise sources (e.g. Stehly et al. 2006) -, inter-station distances to prevent the positive and negative times of the correlation from overlapping (e.g. Stehly et al. 2009) and the range of group velocity expected in the study region.

For each station pair, only measurements fulfilling the selection criteria for both Rayleigh and Love waves are kept in the final dataset. This ensures the same coverage for both types of surface waves at each period, thus resulting in an identical lateral resolution in the 2D tomographic maps. By this way, we avoid differences that may introduce artificial rádial anisotropy in our final 3-D model. Depending on period, we select only $2 \%$ to $19 \%$ of the initial dispersion dataset (Figure 3). A high level of rejection is commonly observed in ambient noise studies (Stehly et al. 2009; Lu et al. 2018). In our case, the lower signal-to-noise ratio on the horizontal components further increases this high level of rejection by excluding Love measurements from the selection. Nevertheless, we keep more than 20,000 station pairs for both Rayleigh and Love waves between 10 and 40 s, with more than 100,000 station pairs around $20 \mathrm{~s}$ period. The selection is designed to investigate radial anisotropy. It ensures identical data coverage for Love and Rayleigh waves but removes a large quantity of useful Rayleigh measurements that could have been used to derive a more detailed $V_{S V}$ model. As a comparison, Lu et al. (2018) use a maximum of 230,000 Rayleigh measurements at $15 \mathrm{~s}$ to build their isotropic $V_{S V}$ model of Europe from ambient noise, corresponding to $30 \%$ of their initial dataset.

\section{2-D SURFACE WAVE TOMOGRAPHY}

\subsection{Inversion method}

Our dataset corresponds to the selected Rayleigh and Love waves group velocity measurements between/station pairs in the period range $5 \mathrm{~s}$ to $149 \mathrm{~s}$. Those group velocities are combined in a tomographic inversion to build 2-D isotropic velocity maps for Rayleigh and Love waves, the maps being generated independently for each period and each type of waves (Rayleigh or Love). The procedure follows the one described in Debayle \& Sambridge (2004) and is a 


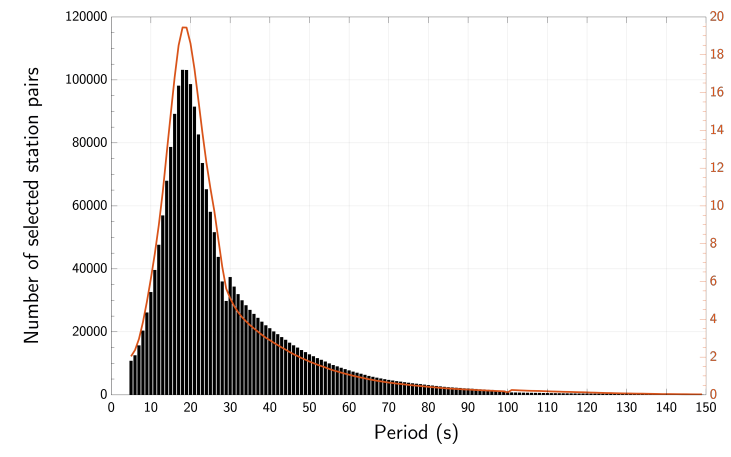

(a)

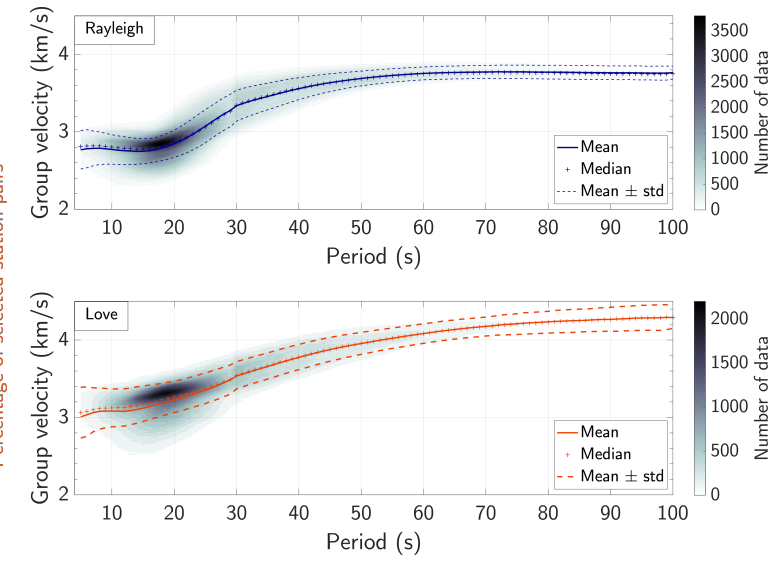

(b)

Figure 3. a) Number of selected station pairs according to period (left axis) and corresponding proportion of the initial dataset (right axis). The selection is performed jointly for Rayleigh and Love group velocity measurements. b) Ensemble of selected Rayleigh and Love dispersion measurements. The number of data is colour coded. The mean and median values are represented as well as one standard deviation from the mean.

classical linearised inversion within the framework of ray theory. Here again, we summarize the method but the reader is referred to the original paper for more details and discussion.

The continuous regionalization approach of Debayle \& Sambridge (2004) uses the least squares solution for linearised inverse problems originally described in Tarantola \& Valette (1982). Within this framework, the problem is linearised around a reference homogeneous velocity model $\mathbf{m}_{0}$ which is defined in our/case as the mean of the observed group velocity measurements at a given period. The regularization is entirely controlled by the choice of $C_{m}$, the a priori model covariance matrix. $C_{m}$ is defined by two parameters: $\sigma_{m}$, the model $a$ priori standard deviation, and $L_{c o r r}$, the horizontal correlation length between two points of the model. $\sigma_{m}$ is the damping parameter which controls the maximum amplitude of velocity perturbations allowed in the final 2-D group velocity model with respect to the reference model $\mathbf{m}_{0}$. It is set to $0.05 \mathrm{~km} / \mathrm{s}$. This value allows to recover large velocity variations in our model, reaching up to $20 \%$ at 8 s period, as can be seen in Figure 4.

The choice of $L_{\text {corr }}$ defines the lateral degree of smoothing in the model. That choice depends on the ray coverage and on the wavelength. After several trials, and taking advantage of the dense coverage available in this study (Figure A.1 in Appendix A), we choose to decrease $L_{\text {corr }}$ with decreasing period according to Table 1 . Using larger values of $L_{\text {corr }}$ would provide smoother maps leading to a poorer fit to the data but would not change the overall result of this study. 
For each wave type, a diagonal matrix $C_{d}$ is defined at each period. Its diagonal terms are $\sigma_{d i}^{2}$, with $\sigma_{d i}$ being the standard deviation of measurement $i$, i.e. the data error. This error $\sigma_{d i}$ is defined at each period as the average of the absolute value of the velocity difference between all causal (positive time of the correlations) and acausal (negative time of the correlation) measurements. Since $\sigma_{d i}$ controls the relative contribution of station pair $i$ to the final model, all station pairs at a given period contribute equally to the model. This is a reasonable choice, as we cannot estimate robust error on the group velocity for each individual station pair.

Within this standard regularized linear inversion scheme, the estimated level of data error and the level of posterior uncertainties are linked to the arbitrarily chosen level of damping (Aster et al. 2018). For this reason, we do not discuss any further errors on the data. In the same way, we do not discuss the uncertainties associated with the 2-D group velocity maps as they are biased by the regularization (see also section 4.4).

The 2-D inverted group velocity model is discretised on a regular grid $\left(0.15^{\circ} \times 0.15^{\circ}\right)$, smaller than the horizontal smoothing imposed on the model, which can be approximated as $\sim 3 L_{\text {corr }}$ (Debayle et al. 2016). This parameterization allows to retrieve lateral heterogeneities of the size of a few tens of kilometers, especially at short periods, while,keeping a reasonable computational cost of few hours maximum per period.

The group velocity maps obtained via our regionalization approach result from an inversion that does not account for Rayleigh and Love wave azimuthal anisotropies. The azimuthal variation for Rayleigh waves depends mostly on the sine and cosine of $2 \psi$, where $\psi$ is the azimuth, and can readily be distinguished from the isotropic component. However, the azimuthal variation of Love waves shows a stronger dependence on $4 \psi$ terms, which need a much better path coverage to be resolved/Smith \& Dahlen 1973). The counterpart is that this faster azimuthal variation should be averaged out more easily by the propagation paths in an isotropic inversion. This is important, because if the propagation paths are sufficient to average over the azimuthal dependency, the inverted velocities in an isotropic tomography should be representative of the average true velocities. If a bias exists, it should be greater for Rayleigh waves because their slower $2-\psi$ variation (with a $\pi$-periodicity) is more difficult to average out than the faster $4-\psi$ variation (with a $\pi / 2$ periodicity ) of Love waves (e.g. Debayle \& Kennett 2000; Sieminski et al. 2003; Debayle \& Ricard 2012). We carried out Rayleigh wave inversion with and without azimuthal anisotropy and we found that both inversions yielded very similar isotropic parts. We concluded that our ray coverage is sufficient to average out properly the azimuthal variations of both Rayleigh and Love waves. We therefore neglect azimuthal anisotropy and only perform isotropic 2-D inversions. 


\begin{tabular}{ccccc}
\hline Period T (s) & $\mathrm{T} \leq 20$ & $20<\mathrm{T} \leq 50$ & $50<\mathrm{T} \leq 100$ & $100<\mathrm{T}$ \\
\hline $\mathbf{L}_{\text {corr }}(\mathbf{k m})$ & 20 & 25 & 50 & 100 \\
\hline
\end{tabular}

Table 1. Correlation lengths used in the tomographic inversion depending on period. This parameter controls the smoothing of the final model.

To asses the parts of the model that are well resolved given the ray coverage, parameterization and the regularization used, we carried out a number of synthetic tests shown in Appendix B.

\subsection{Group velocity maps}

Group velocity maps for Love and Rayleigh waves are shown at $8 \mathrm{~s}, 30 \mathrm{~s}$ and $55 \mathrm{~s}$ periods in Figure 4. The corresponding ray densities are shown in Figure A.1 in Appendix A. Additional group velocity maps are shown in Figure C.1 in Appendix C for periods 60, 80 and $110 \mathrm{~s}$. Here we only discuss results for periods 8,30 and 55 s since some smearing affects a large part of the study area at longer periods.

At $8 \mathrm{~s}$, both Love and Rayleigh waves are sensitive to the upper crust. In agreement with previous studies conducted from ambient noise in the area (e.g. Stehly et al. 2009; Molinari et al. 2015; Kästle et al. 2018; Lu et al. 2018, 2020), the low velocity zones in our model highlight the main sedimentary basins such as the Southeast basin in France, the Alpine molasse basin, the Po plain and to a lesser extent the Vienna, Pannonian and Aquitanian basins that are close to the boundaries of the study area. High velocity anomalies are in contrast associated with mountain belts such as the Alps, Apennines, Dinarides or Pyrenees. Variscan massifs are also associated with high velocities: Armorican Massif and Massif Central in France, and even more clearly the Bohemian Massif which is clearly visible on both Rayleigh and Love maps.

At $30 \mathrm{~s}$, surface waves are mostly sensitive to the lower crust and the uppermost mantle. Low velocity anomalies observed in the Alps, Apennines and Dinarides are therefore attributed to the crustal roots of these orogens. Interestingly, the Love wave low velocity anomaly is stronger beneath the Apennines than beneath the Alps, while these differences are not observed for Rayleigh waves. A possible explanation is based on the studies of Chiarabba \& Amato (1996); Chiarabba et al. (2009); Di Stefano et al. (2009) who conclude that very high temperatures, and so very low seismic velocities, can be observed in the lower crust of the Apennines. The lower crust of the Apennines would therefore be associated with a stronger velocity reduction than the lower crust of the Alps. With this in mind, we can argue that 
Rayleigh

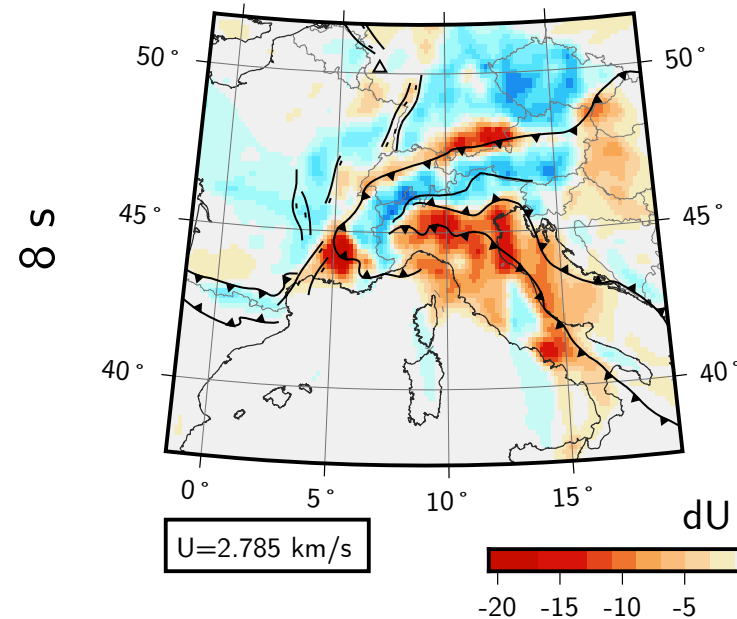

$\begin{array}{lllllllll}-20 & -15 & -10 & -5 & 0 & 5 & 10 & 15 & 20\end{array}$

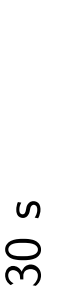

$$
50^{\circ}
$$

$50^{\circ}$
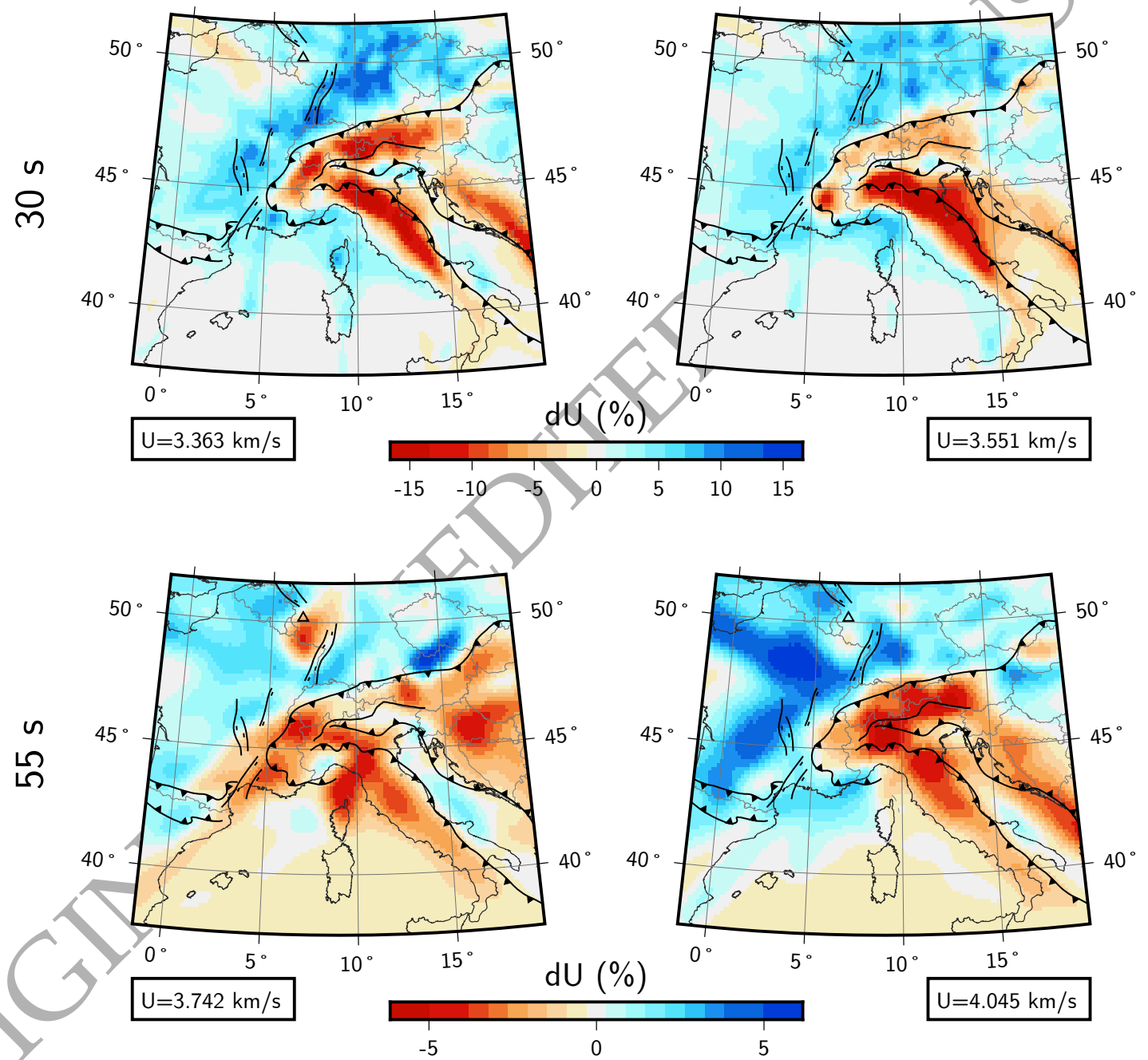

2

Figure 4. Group velocity perturbation maps for Rayleigh and Love waves at periods 8,30 and $55 \mathrm{~s}$.

The reference group velocity $U$ is indicated below each map. Major sedimentary basins, mountain belts, and Variscan massifs are clearly visible. 
Love waves at $30 \mathrm{~s}$ period are sensitive to the hot and very low-velocity lower crust above the shallower Moho beneath the Apennines and to mid-crustal velocities above the deeper Moho beneath the Alps (e.g. Spada et al. 2013) thus leading to a stronger low velocity anomaly in the Apennines. However, due to their slightly deeper sensitivity at the same period, Rayleigh waves would pick up the very low velocity above the Apenninic Moho but also the higher mantle velocities at slightly greater depths, resulting in an average low velocity anomaly similar in strength to the ones observed above the deeper Moho of the Alps where the waves are primarily sensitive to the lower crust.

The pattern of velocity anomalies observed at $55 \mathrm{~s}$ suffers from some smearing of the high velocity anomalies, mostly in France (see also ray density maps in Figure A.1). Several features are nonetheless clearly observable. A strong Rayleigh wave low-velocity anomaly and a weaker low-velocity Love wave anomaly roughly coincide with the Eifel volcanic region in Western Germany. In this region, the lithosphere-asthenosphere boundary (LAB) is approximately at 40-50 km depth (e.g. Mathar et al. 2006; Seiberlich et al. 2013). The relative shallowness of the LAB is suggested to be linked to the presence of a thermal anomaly that spreads at the bottom of the lithosphere (e.g. Ritter et al. 2001; Keyser et al. 2002; Pilidou et al. 2005), affecting to a lesser extent the thermal state of the lithosphere itself (Schintgen et al. 2015). The difference in velocity anomalies seen between Rayleigh and Love waves maps may be due to the deeper penetration of Rayleigh waves, sampling at this period the top of the low velocity asthenosphere, while Love waves would mostly be sensitive to the colder lithosphere, which is still slightly hotter than its surroundings. The differences between the Love and Rayleigh patterns beneath the Alps, Apennines and Dinarides clearly suggest the presence of strong velocity and radial anisotropy variations in the lower crust and uppermost mantle.

\section{BAYESIAN INVERSION FOR VELOCITY AND ANISOTROPY AT DEPTH}

In this section we describe how we invert group velocity maps for a 3-D model of shear wave velocity and radial anisotropy. At each geographical location, we use both Love and Rayleigh group velocities from $5 \mathrm{~s}$ to $149 \mathrm{~s}$ with a step of $5 \mathrm{~s}$, and perform a 1-D inversion within a transdimensional Bayesian framework (Bodin et al. 2012a,b; Yuan \& Bodin 2018). 

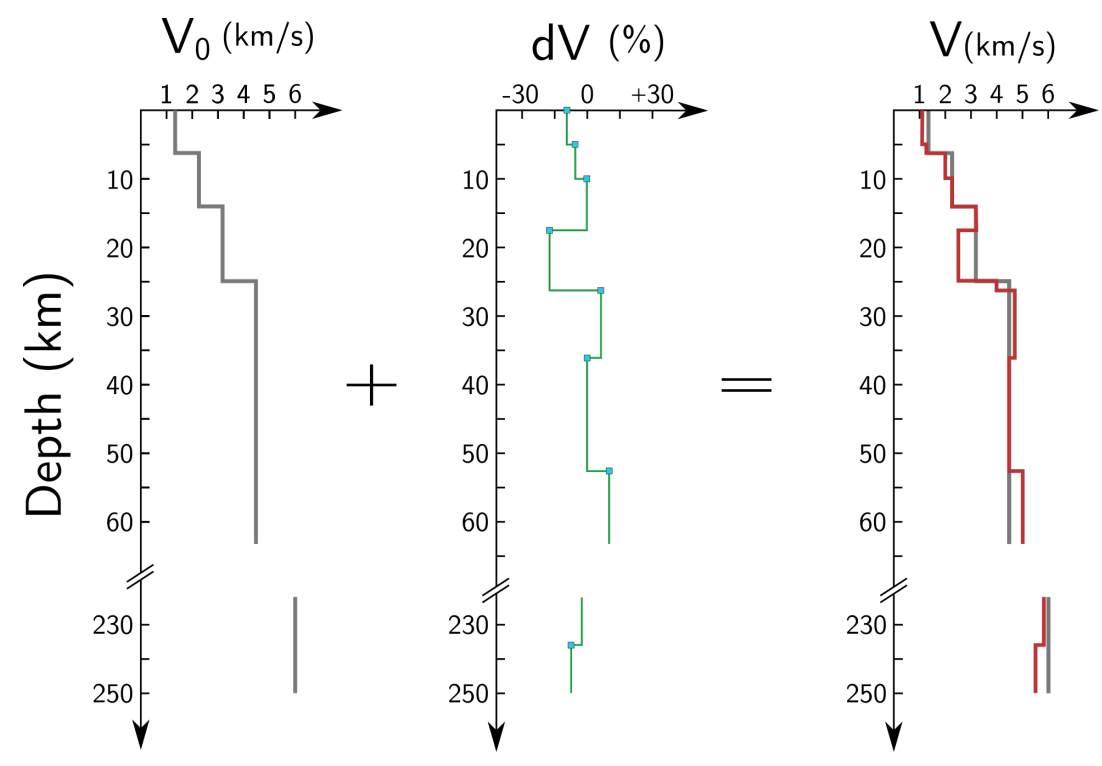

Figure 5. Illustration of the model parameterization: (left) layered reference model $V_{0}(z)$ that remains fixed during the inversion; (middle) model of velocity variations $d V(z)$ defined by layers whose number, thickness, and velocity change $d V$ are unknowns of the inversion; (right) final model constructed by adding the perturbations to the background model.

\subsection{Model parameterization}

Since Love waves are primarily sensitive to $V_{S H}$ and to a lesser extent to $V_{S V}$, and Rayleigh waves are primarily sensitive to $V_{S V}$, and to a lesser extent to $V_{P}$, we invert for the $V_{S V}$ structure, the $V_{P} / V_{S V}$ ratio, and radial anisotropy defined by the ratio $V_{S H} / V_{S V}$.

Because sharp discontinuities cannot be resolyed by surface waves alone, we impose the depth of discontinuities from an isotropic reference velocity structure based on the $V_{S V}$ model of $\mathrm{Lu}$ et al. (2018), which is defined at each geographical point as a stack of layers and depicts Moho topography as well as isotropic smooth lateral $V_{S V}$ variations for the crust and uppermost mantle, down to $80 \mathrm{~km}$ depth. At greater depths, Lu et al. (2018)'s model is combined with PREM (Dziewoński \& Anderson 1981) down to $670 \mathrm{~km}$ depth. As described in Yuan \& Bodin (2018), we invert for perturbations around this reference model, which remains unchanged during the procedure. The velocity $V_{S V}(z)$ at depth $z$ is then a combination of the reference model $V_{0}$ and the inverted model $d V$ :

$$
V_{S V}(z)=V_{0}(z)(1+d V(z))
$$

Figure 5 illustrates the different elements of this parameterization in a schematic way.

The inverted model $d V(z)$ is parameterized as a stack of layers, where the thickness and the $V_{S V}$ perturbation in each layer are unknown parameters. Note that these perturbations 
do not need to be small, as there is no linearisation involved in the forward calculation of dispersion curves. The ratios $V_{S H} / V_{S V}$ and $V_{P} / V_{S V}$ in each layer of the inverted model are also free parameters. The density $\rho$ is simply scaled on $V_{P}$ following an empirical Birch's law (Birch 1961) for the lithosphere in the form $\rho=2.35+0.036\left(V_{P}-3\right)^{2}$ as in Tkalčić et al. (2006). To account for the sensitivity of the longest-period surface waves in our dataset to upper-mantle shear velocity, the inverted model is parameterized from the surface to $250 \mathrm{~km}$ depth. However, we only show results from our final 3-D model down to maximum $120 \mathrm{~km}$ depth, as we estimate the resolution to be too low at greater depths.

\subsection{A transdimensional approach}

As mentioned in the introduction, a strong trade-off exists between radial anisotropy, created by LPO of anisotropic minerals, and vertical heterogeneities, i.e. horizontal layering (see e.g. Backus 1962; Bodin et al. 2015; Alder et al. 2017). Our inverse problem is then highly nonunique since a model with many isotropic layers explains the data as well as a model with fewer anisotropic layers. To address this non-uniqueness, we place ourselves in a transdimensional Bayesian framework where the number of model parameters is unknown. This means that the total number of layers in the inverted model as well as the presence of anisotropy in each layer are not fixed parameters but they are adjusted by the inversion to fit the data to the degree required by their estimated noise. Each layer in the inverted model can be either isotropic and described solely by its shear wave velocity perturbation $d V$, and $V_{P} / V_{S}$ ratio (in this case, $V_{S H} / V_{S V}$ is fixed to unity), or radially anisotropic and described by three parameters: $d V$, $V_{P} / V_{S}$, and $V_{S H} / V_{S V}$

\subsection{Bayesian inference}

Within a Bayesian framework, each piece of information is treated in a probabilistic way. The solution of our inverse problem is a large ensemble of layered models distributed according to the posterior probability distribution $p\left(\mathbf{m} \mid \mathbf{d}_{o b s}\right)$, which represents the probability density of model $\mathbf{m}$ given the observed dispersion curves $\mathbf{d}_{o b s}$ (and given the reference model $V_{0}$ ). According to Bayes' theorem,

$$
\begin{aligned}
& p\left(\mathbf{m} \mid \mathbf{d}_{o b s}\right) \propto p\left(\mathbf{d}_{o b s} \mid \mathbf{m}\right) \times p(\mathbf{m}) \\
& \text { posterior } \propto \text { likelihood } \times \text { prior }
\end{aligned}
$$


the posterior probability distribution $p\left(\mathbf{m} \mid \mathbf{d}_{o b s}\right)$ is a function of the prior $p(\mathbf{m})$ and the likelihood function $p\left(\mathbf{d}_{o b s} \mid \mathbf{m}\right)$. The prior represents the state of knowledge of the model before taking into account the data, whereas the likelihood function is the probability of observing the measured dispersion curves given a particular model.

In the context of a Bayesian inversion, the level of data noise (both observational and theoretical errors) is an important parameter as it controls the required level of fit to the observed dispersion curves and hence the required level of complexity in the solution (e.g. Sambridge et al. 2013). This is achieved through the form of the likelihood function $p\left(\mathbf{d}_{o b s} \mid \mathbf{m}\right)$ which is based on a statistical model of data errors. Here, we assume a Gaussian distribution for data errors, and hence the likelihood is based on a least squares misfit function in the form

$$
p\left(\mathbf{d}_{\text {obs }} \mid \mathbf{m}\right)=\frac{1}{(\sqrt{2 \pi})^{2 n} \times\left(\sigma_{R} \sigma_{L}\right)^{n}} \times \exp \left\{-\frac{1}{2}\left(\frac{\left\|\mathbf{U}_{R}-\mathbf{u}_{R}(\mathbf{m})\right\|^{2}}{\sigma_{R}^{2}}+\frac{\left\|\mathbf{U}_{L}-\mathbf{u}_{L}(\mathbf{m})\right\|^{2}}{\sigma_{L}^{2}}\right)\right\}(3)
$$

where $\sigma_{R}^{2}$ and $\sigma_{L}^{2}$ respectively refer to the variance of the estimated errors for Rayleigh and Love data, $n$ is the number of points in the dispersion curves (which is the same for Love and Rayleigh waves), $\mathbf{U}_{R}$ and $\mathbf{U}_{L}$ are the observed dispersion curves for Rayleigh and Love waves respectively, and $\mathbf{u}_{R}(\mathbf{m})$ and $\mathbf{u}_{L}(\mathbf{m})$ are Rayleigh and Love dispersion curves estimated for model $\mathbf{m}$ (Bodin et al. 2016). Regarding the forward modelling step, Love and Rayleigh dispersion curves are computed with a normal mode formalism in a spherical Earth (Smith \& Dahlen 1973). The estimation of fundamental mode group velocities is made in a fully nonlinear fashion with a Runge-Kutta matrix integration (Saito 1967; Takeuchi \& Saito 1972; Saito 1988).

Here we use a transdimensional framework, where the number of parameters is unknown. Therefore, one might think that adding parameters in the model can help fitting the data at the level required by their quality. However, transdimensional Bayesian inversions are parsimonious, which means that, for a given level of required data fit, simpler models with fewer parameters are preferred over complex ones (e.g. Sambridge et al. 2013). In our case, models with fewer and isotropic layers will then be preferred. Any anisotropy recovered by a model is therefore only that required by the data.

\subsection{Hierachical Bayes}

The estimation of data errors is a well-known issue as both theoretical and observational errors are often difficult to estimate. This is particularly crucial here as underestimating noise would introduce more structure in the solution model to fit the data at a non-necessary level, whereas overestimating errors would lead to smooth models that miss resolvable structure. 


\begin{tabular}{cccccc}
\hline Layer thickness $(\mathrm{km})$ & $d V(\%)$ & $V_{S H} / V_{S V}$ & $\frac{V_{P}}{V_{S V}}$ & $\sigma_{R}$ and $\sigma_{L}(\%)$ & Nb. of layers \\
\hline $2-+\infty$ & \pm 30 & $0.8-1.2$ & $1.6-1.9$ & $0.2-3$ & $3-300$ \\
\hline
\end{tabular}

Table 2. A priori information used in the Bayesian inversion.

Here, the data are the group velocities at each geographical point of the tomographic maps obtained after the first inversion in 2-D. The estimation of errors on these maps is computationally too expensive for a tomographic problem of this size (Debayle \& Sambridge 2004). In addition, uncertainties on the maps are bounded by the arbitrary choice of regularization and data errors estimated before the 2-D inversion and may not be seen as an objective estimation of uncertainties (Tarantola \& Valette 1982). This is because regularization or damping helps to stabilize the inversion of linear systems of equations and suppresses propagation of data noise into the solution, but this is at the cost of biasing the solution in a statistical sense (Aster et al. 2018). In this way, uncertainties in the 2-D group velocity maps cannot be propagated and used as 'data errors' in the 1-D depth inversion.

To overcome this lack of knowledge of data noise, we extend the Bayesian formulation of the problem and use a hierarchical Bayes model (Malinverno \& Briggs 2004; Bodin et al. 2012a) where the data errors $\sigma_{R}$ and $\sigma_{L}$ are not fixed but are treated as unknown parameters to be inverted for. Although we ensured that Rayleigh and Love group velocity maps are produced with the same ray coverage, Rayleigh and Love measurements are made on different components and contain different levels of error For this reason, we use two separate unknown variables $\sigma_{R}$ and $\sigma_{L}$ for the level of errors associated with each wave type.

\subsection{Prior distribution}

For each of the parameters involved in our inversion, the prior knowledge is represented by a uniform a priori distribution. The bounds of the distributions are summarized in Table 2 . For example, the prior on the vector of velocity perturbations $\mathbf{d V}$ in a model with $k$ independent layers is, in this case

$$
p(\mathbf{d} \mathbf{V} \mid k)=\left(\frac{1}{d V_{\max }-d V_{\min }}\right)^{k}
$$

with $d V_{\min }$ and $d V_{\max }$ respectively the lower and upper bounds of the prior. The uniform distributions of the total number of layers and of the number of anisotropic layers are taken as broad as possible, typically from 3 layers to several hundreds. These choices of the prior knowledge allow to explore a broad range of model variations, with the idea to allow large velocity amplitude variations and to explore trade-offs between parameters. 


\subsection{Sampling the posterior distribution}

To deal with the variable dimension of the model space imposed by the transdimensional framework, we sample the posterior probability distribution using a reversible jump Markov chain Monte Carlo (rj-McMC) algorithm (Green 1995). Starting from the isotropic reference model, the method consists of an iterative random walk in the model space. At each iteration of the chain, a specific move from the current model $d V(z)$ is selected at random and with equal probability from the following possibilities:

(1) select a random layer, and perturb the value of $V_{S V},(2)$ select a random layer, and perturb the value of $V_{P} / V_{S V}$, (3) select a random anisotropic layer, and perturb the value of $V_{S H} / V_{S V}$, (4) modify the thickness of a random layer, (5) add or remove an isotropic layer at a random depth, (6) add or remove anisotropy in an existing random layer, (7) randomly modify the level of data noise. These perturbations only affect the inverted layered model and not the reference model which remains fixed during the whole procedure (see Section 4.1). At each iteration, a new model is proposed that only depends on the previous one. The new model is either accepted or rejected in the ensemble solution, depending on acceptance criteria based on the comparison of the likelihoods of the current and proposed models. The ensemble of accepted models asymptotically converges towards the posterior distribution (for details, see Bodin et al. 2012a).

Finally, the ensemble solution at each point is a probabilistic distribution of 70,000 layered models of $V_{S V}$, radial anisotropy and $V_{P} / V_{S V}$ as a function of depth. We will see in Section 4.7 that although the inversion for $V_{P} / V_{S}$ is useful to avoid introducing biases on other parameters, this parameter is poorly constrained due to the weak and null sensitivity to $V_{P}$ of Rayleigh and Love waves respectively. We therefore do not interpret the 3-D variations in $V_{P} / V_{S V}$ and focus on $V_{S V}$ and radial anisotropy. 1-D profiles of $V_{S V}$ and radial anisotropy that we consider representative of the ensemble solution are then extracted from the posterior distributions. They are finally assembled in a single 3-D model of the crust and uppermost mantle of Europe.

\subsection{Synthetic tests}

To discuss the resolving power of our method, we carry out several tests by jointly inverting Rayleigh and Love synthetic dispersion curves to which a white Gaussian noise of $0.3 \%$ has been added. For each test, whose results are shown in Figures 6, 7 and 8, the solution is a large ensemble of layered models whose distribution is displayed to $120 \mathrm{~km}$ depth. In all cases, the median of each posterior distribution, i.e. the median over the large ensemble of solution 
models, becomes a smooth function of depth because the depth of discontinuities in individual models is variable. Only the discontinuities present in the reference model are preserved in the median model.

It is important to note that at a given depth, each sampled model can either be isotropic or anisotropic. In this way, the distribution of the $V_{S H} / V_{S V}$ parameter contains a large number of values equal to unity, which explains why the median of the anisotropic parameter is often exactly equal to unity. We therefore consider a median value different from unity as a reliable indication for the presence of anisotropy.

Panels a), c), e) in Figure 6 show that the general $V_{S V}$ structure is relatively well retrieved below Moho depth, not only in its tendency but also in its absolute value. However, at depths shallower than $30 \mathrm{~km}$ on panels a) and c), we are only able to capture the general velocity increase instead of the sharp variations imposed in the true models. The Moho in the ensemble solution is imposed by the reference model, as implied by our particular method.

As expected, radial anisotropy is less constrained than $V_{S V}$ : its posterior distribution is quite wide. In the case where the true model is isotropic (panel a) in Figure 6, the median value for $V_{S H} / V_{S V}$ is strictly equal to unity, which is the true value. As shown in Figure 7, this would not be the case if anisotropy was imposed at all depths as an unknown parameter to be inverted for. Spatial variations of anisotropy are well retrieved (panels c) and e) in Figure 6), but the absolute level of anisotropy, both in positive $>1)$ and negative $(<1)$ values, is always underestimated by the median of the distribution.

As surface waves are not sensitive enough to $\mathrm{V}_{P}$, the $\mathrm{V}_{P} / \mathrm{V}_{S V}$ ratio is not constrained at all and we do not interpret it. Of course, fixing $V_{P} / V_{S V}$ in the inversion to the correct value would allow a better recovery of the amplitude of radial anisotropy. However, we do not know the actual 1-D profile of $\mathrm{V}_{P} / \mathrm{V}_{S V}$, and there is a risk to bias the results if we fix the $\mathrm{V}_{P} / \mathrm{V}_{S V}$ ratio to a wrong value. In the context of a Bayesian formalism, it is therefore more sensible to use a wide a priori distribution for $\mathrm{V}_{P} / \mathrm{V}_{S V}$ and to treat it as an unknown parameter, although we do not interpret its wide and poorly informative a posteriori distribution. Since $\mathrm{V}_{P}$ and density are scaled on one another, we could have inverted for $\rho$ instead of $\mathrm{V}_{P} / \mathrm{V}_{S V}$. However, the density would not have been better constrained because surface waves have no sensitivity to this parameter.

From the tests shown in Figure 6, we conclude that the best resolved parameters are $\mathrm{V}_{S V}$ and radial anisotropy. We cannot resolve sharp discontinuities in these parameters but we recover well their variations, although radial anisotropy amplitudes are somewhat underestimated. 


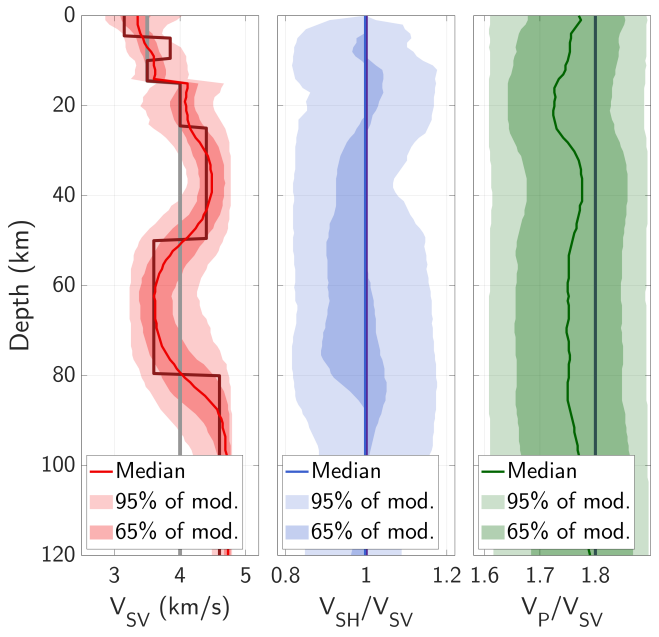

(a)

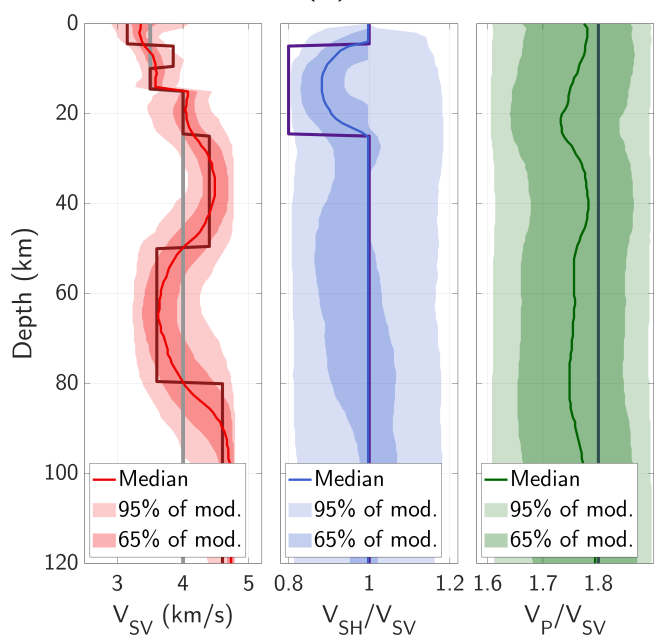

(c)

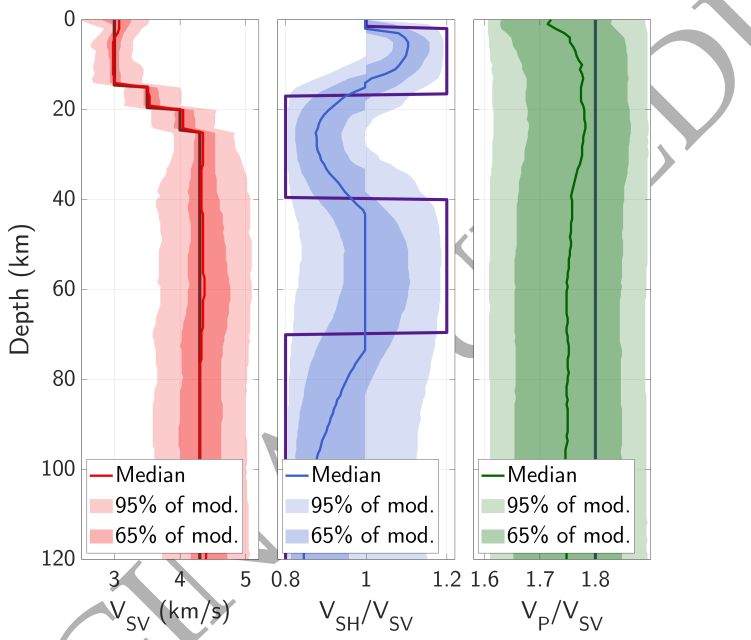

(e)

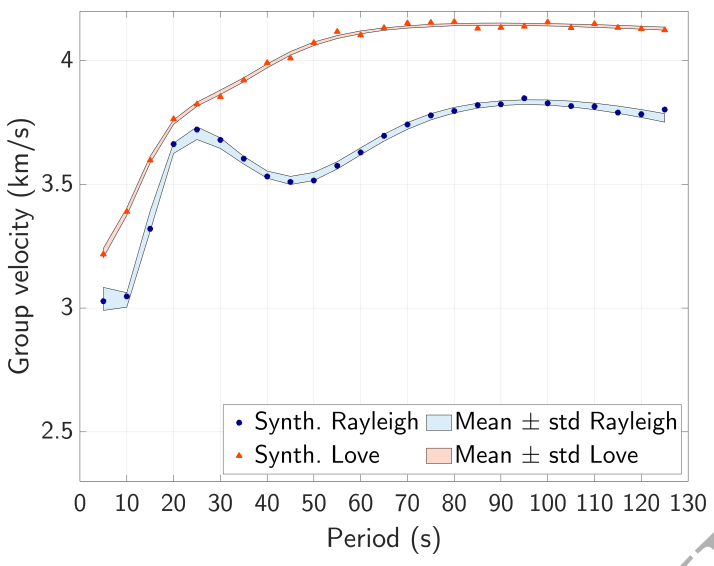

(b)
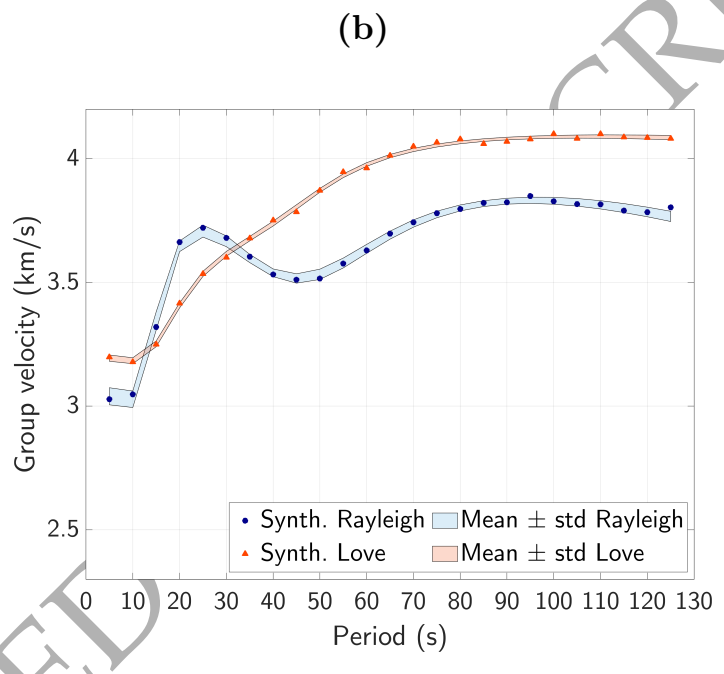

(d)

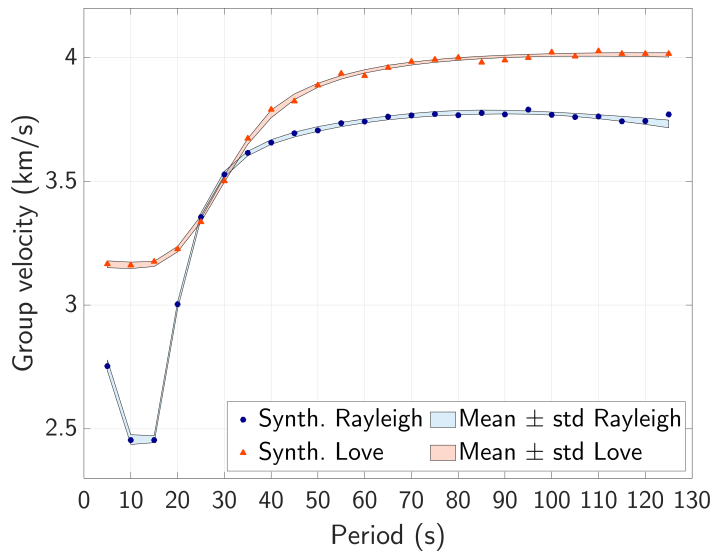

(f)

Figure 6. Synthetic tests. Left panels: posterior distributions of $V_{S V}$ (red), $V_{S H} / V_{S V}$ (blue) and $V_{P} / V_{S V}$ (green). For each case (a, c, e), the true model is the thick solid line in every panel and the reference velocity model used in the inversion is the grey line in $V_{S V}$ panel. Posterior distributions are depicted with their median (thin solid line) and likelihood intervals: for each parameter, the dark surface includes $65 \%$ of the models in the ensemble solution while the light area includes $95 \%$ of the models. Right: synthetic data (coloured dots) calculated from the true model and interval of mean \pm standard deviation of group velocity data calculated from the inverted models (coloured area). 
In addition, while the ensemble solution is broadly spread in the model space, the associated data distribution in Figure 6 is relatively narrow and close to synthetic data. This clearly shows the non-uniqueness of the inverse problem given the flexible parameterization used here.

In Figure 7, we illustrate the benefit of this flexible parameterization where each layer can be either isotropic or anisotropic. A true model is designed with an anisotropic layer in the crust and an isotropic upper crust and mantle. Noisy synthetic data are created and inverted with two procedures. We compare our procedure (left panels) with a more standard approach where anisotropy is imposed and inverted at all depths (right panels). Everything else is equal in the two inversions, e.g. the number of layers is variable in both cases. Although $V_{S V}$ is equally well resolved in both cases, the anisotropic layer in the crust is better recovered with our flexible scheme. In the mantle, where the true model is isotropic, the ensemble solution produced by our scheme includes a large number of isotropic models, resulting in a narrower distribution for $V_{S H} / V_{S V}$ and a median value equal to unity. Conversely, the more standard approach documented in the right panels leads to a wider distribution of anisotropy and gives a median $V_{S H} / V_{S V} \approx 0.95$. This comparison shows that in the case of a true isotropic model, our flexible scheme fits data with simpler isotropic models described by fewer parameters, resulting in a distribution closer to the true model.

In Figure 8, we test our scheme in the case of isotropic models including a large number of horizontal interfaces, where the layer thickness in the true model is much smaller than what can be resolved by surface waves at these periods. The goal here is to test whether thin horizontal layering is going to be mapped into radial anisotropy. Layering in the continental lower crust of the Variscan provinces of Western Europe is known to exist from deep seismic reflection profiles, and it is interpreted as resulting from intrusions of mafic/ultramafic rocks derived from the upper mantle alternating with felsic granulitic lower crustal rocks (Singh \& McKenzie 1993). Here, we design a model with a 30-km thick crust where the lower half of the crust (i.e. between $15 \mathrm{~km}$ and $30 \mathrm{~km}$ depth) is composed of a stack of 150 lamellae of $100 \mathrm{~m}$ thickness with $V_{S V}$ velocities alternating between $3.33 \mathrm{~km} / \mathrm{s}$ and $4.07 \mathrm{~km} / \mathrm{s}$, i.e. $+/-10 \%$ around $3.7 \mathrm{~km} / \mathrm{s}$, resulting in a peak-to-peak level of heterogeneity of $20 \%$. This corresponds to the model proposed by Paul \& Nicollin (1989) to explain the frequency dependent attenuation of the $P$ M phase observed in wide-angle data collected along the North of France deep seismic reflection ECORS profile. Left panels in Figure 8 show that in this case, no artificial anisotropy is recovered in the inverted model, as a majority of sampled profiles can explain both Love and Rayleigh waves data without the need for anisotropy. Similar results are observed for velocity 


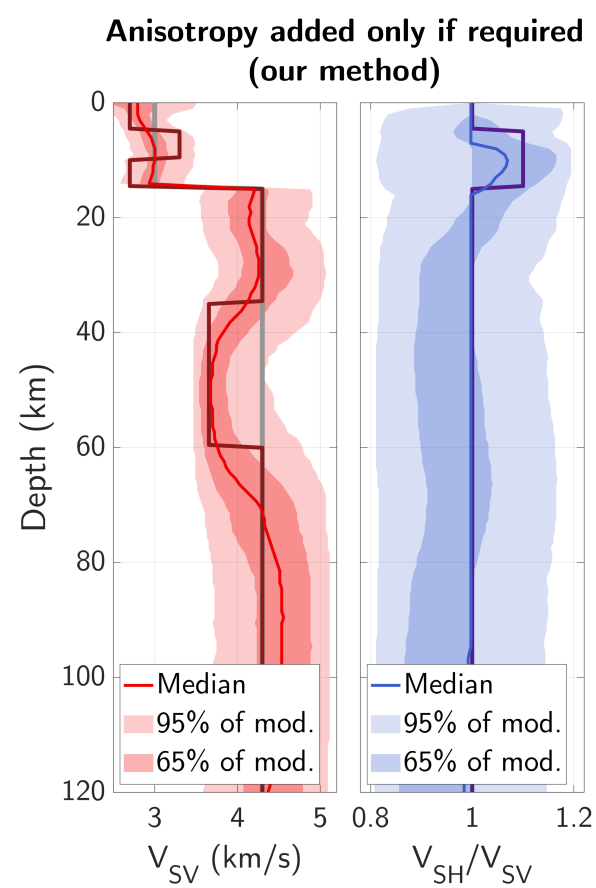

(a)

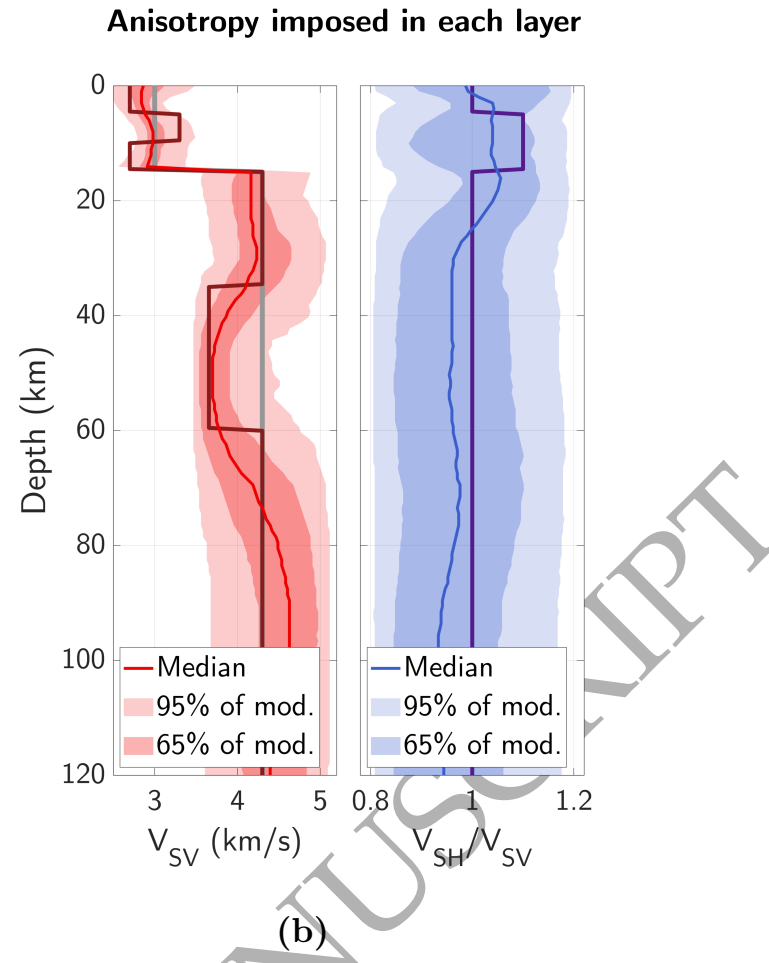

(b)

Figure 7. Synthetic tests where the same data produced by the true model are inverted with two different procedures. Left panels: inversion used in this study, where each layer can either be isotropic or anisotropic. Right panels: inversion where anisotropy is imposed as an unknown parameters at all depths. See legend of Figure 6for the meaning of the different lines and colours.

contrasts reaching up to $30 \%$. The second model tested in the right panels of Figure 8 shows a stronger level of heterogeneity with $V_{S V}$ alternating between $2.96 \mathrm{~km} / \mathrm{s}$ and $4.44 \mathrm{~km} / \mathrm{s}$, i.e. $+/-20 \%$ around $3.7 \mathrm{~km} / \mathrm{s}$, resulting in a peak-to-peak level of heterogeneity of $40 \%$. This model is much less realistic as heterogeneities are stronger than what can be expected in the lower crust (Paul \& Nicollin 1989; Singh \& McKenzie 1993). In this case, the algorithm adds radial anisotropy to fit data, resulting in a $10-\mathrm{km}$ thick anisotropic layer at the base of the crust in the median model. From these tests, we conclude that thin hectometric layering with up to $30 \%$ velocity contrasts will not map into anisotropy in our median posterior model, even though a large number of individual models in the ensemble solution depict anisotropy. This will be useful to interpret our 3-D anisotropic model of Europe.

\section{RADIALLY ANISOTROPIC 3-D MODEL}

We apply the 1-D inversion presented above at each geographical location and obtain a 3-D probabilistic model of the study area. Figure 9 and Figure 10 present 4 depth slices at 8 , 


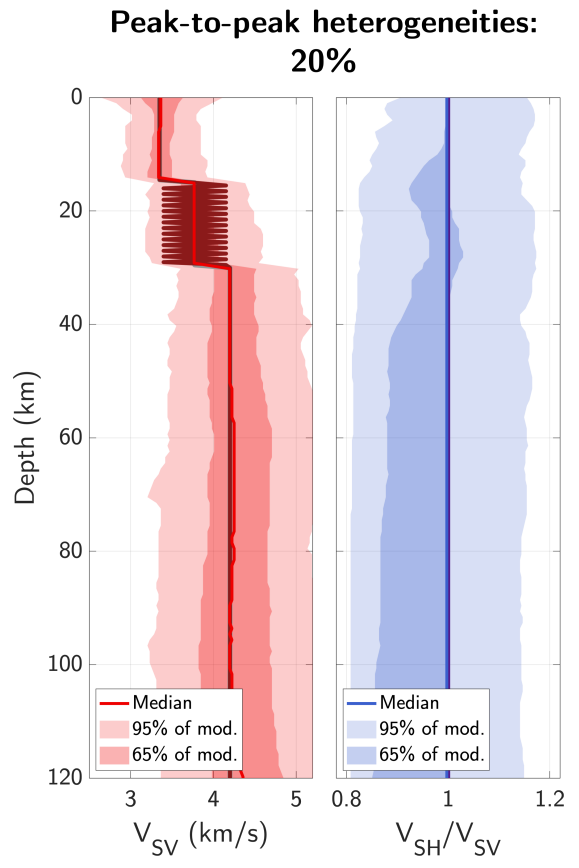

(a)

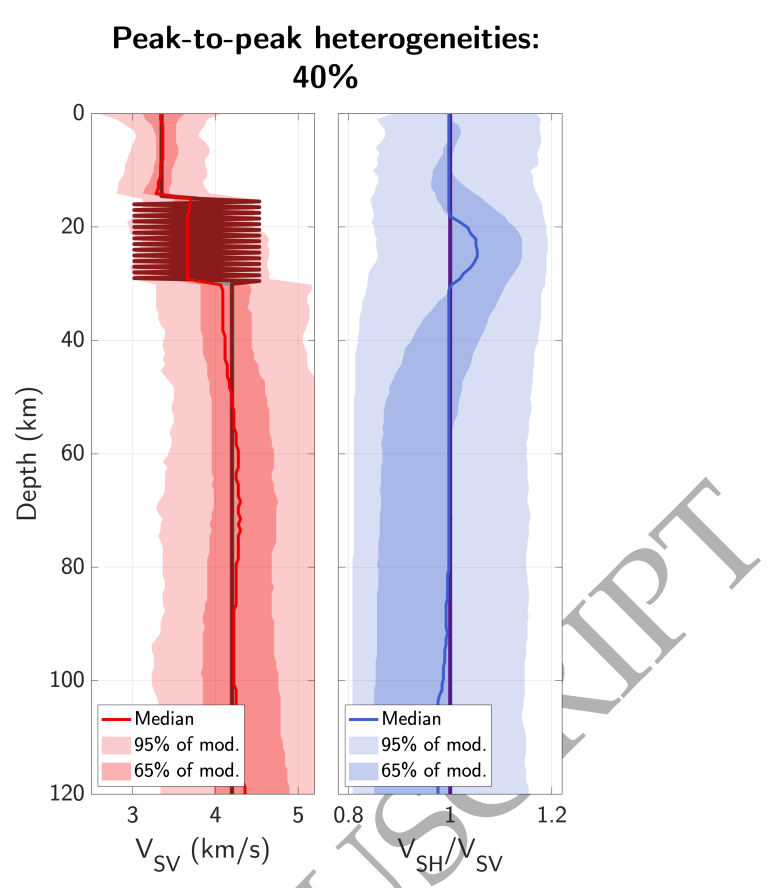

(b)

Figure 8. Synthetic tests where the lower crust in the true model is made of a stack of 150 identical lamellae of thickness $100 \mathrm{~m}$, alternating between high and low velocities. Left: results where the lower crustal velocities in the true (target) model alternate between $V_{S V}=3.33 \mathrm{~km} / \mathrm{s}$ and $V_{S V}=4.07 \mathrm{~km} / \mathrm{s}$ (i.e. $+/-10 \%$ around $3.7 \mathrm{~km} / \mathrm{s}$, resulting in a peak-to-peak level of heterogeneity of $20 \%$ ). Right: results where the lower crustal velocities alternate between $V_{S V}=2.96 \mathrm{~km} / \mathrm{s}$ and $V_{S V}=4.44 \mathrm{~km} / \mathrm{s}$ (i.e. $+/-20 \%$ around $3.7 \mathrm{~km} / \mathrm{s}$, resulting in a peak-to-peak level of heterogeneity of $40 \%$. See legend of Figure 6for the meaning of the different lines and colours.

32, 50 and $70 \mathrm{~km}$ in our final 3-D model. We show the posterior median $\mathrm{dV}_{S V}$ and radial anisotropy models in the upper and middle parts of each figure, respectively. The lower panels of the figures show the probability that anisotropy takes a positive $\left(V_{S H}>V_{S V}\right)$ or negative $\left(V_{S H}<V_{S V}\right)$ value. This probability is the number of models with positive or negative anisotropy expressed as a percentage of the total number of models. Figure 11 and Figure 12 show cross-sections in our model. The level of data fit of our 3-D probabilistic model is shown in Figure D.1.

\subsection{Velocity structure}

As explained before, the rejection of a large number of Rayleigh wave dispersion data in the selection procedure (see Section 2.2) implies that the resolution of our $V_{S V}$ model is lower than that of models built from larger Rayleigh waves dispersion datasets (e.g. Lu et al. 2018). 
$8 \mathrm{~km}$
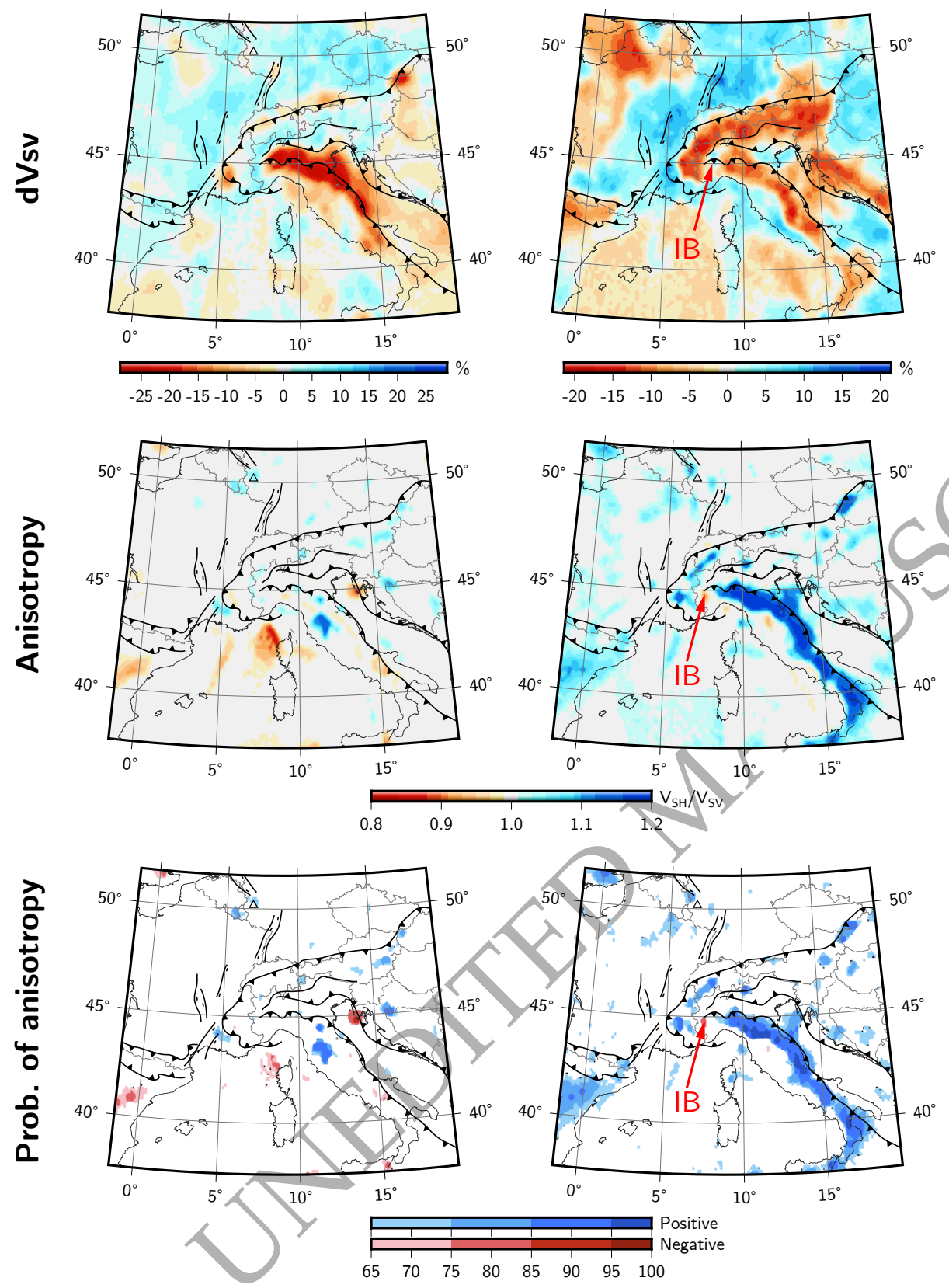

Figure 9. Depth slices at 8 and $32 \mathrm{~km}$ in our 3-D model displaying the posterior median model of velocity as perturbations around the mean of the map (top panels), the median radial anisotropy as the inverted parameter $V_{S H} / V_{S V}$ (middle panels) and the probability of positive (blue) and negative (red) radial anísotropy (bottom panels). IB: Ivrea Body.

$32 \mathrm{~km}$

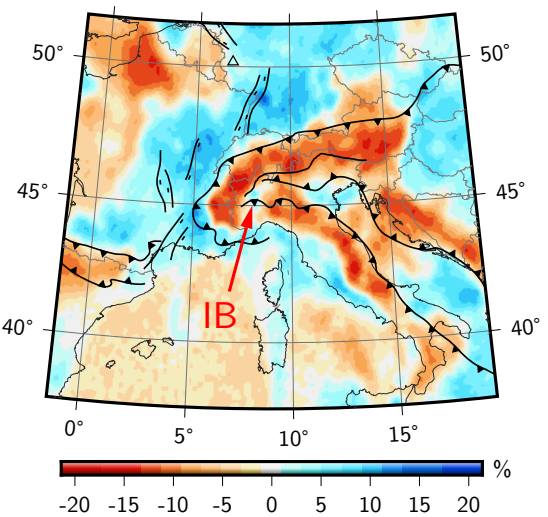

2 
$50 \mathrm{~km}$
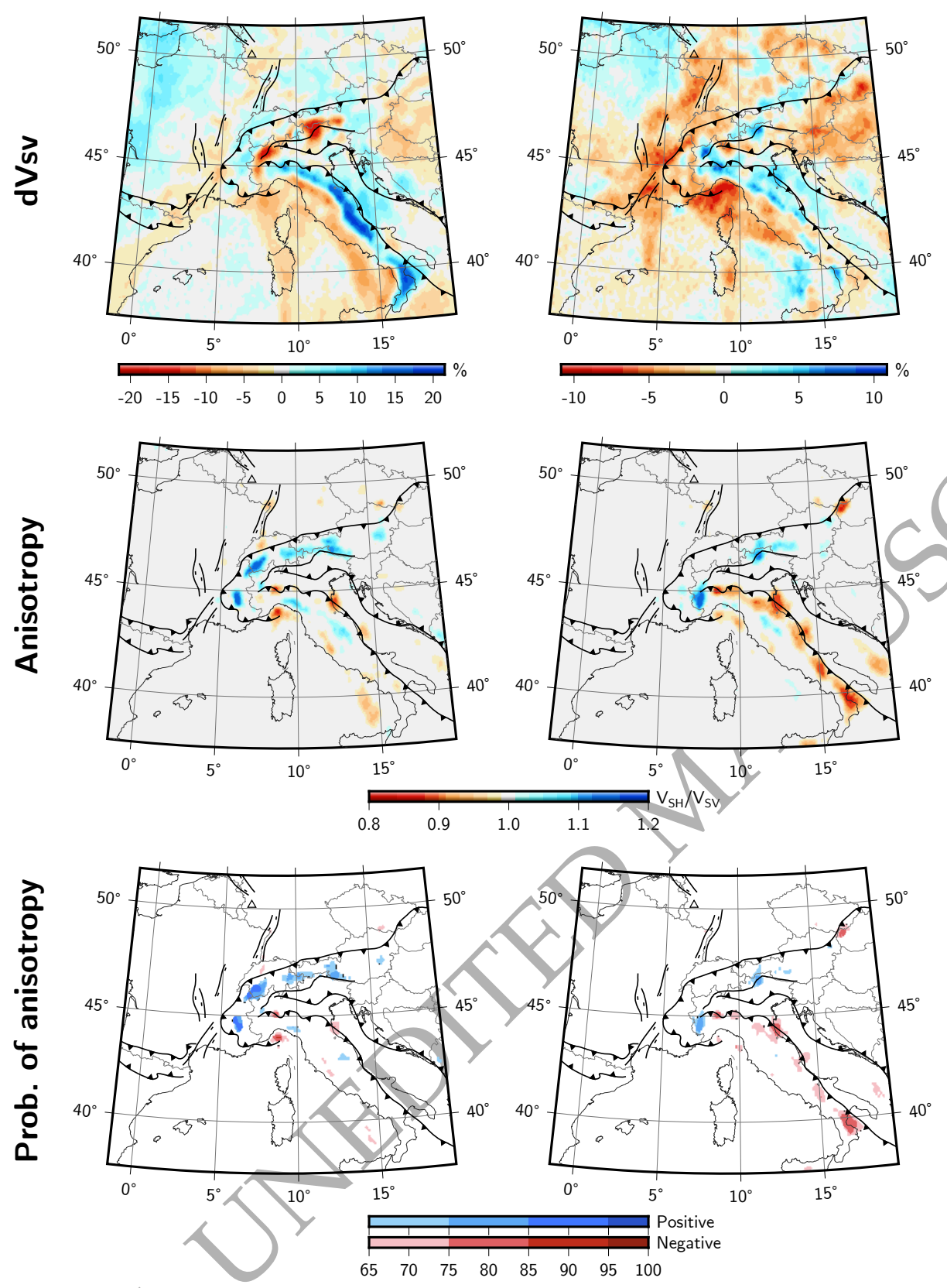

Figure 10. Same as Figure 9 but for depths 50 and $70 \mathrm{~km}$.

The main focus of this work is therefore to image radial anisotropy in the crust and upper mantle of Europe. However, this work benefits from a good data coverage (see Figure A.1 in Appendix) which allows to image a few features that deserve to be briefly described in the following.

In the upper crust ( $8 \mathrm{~km}$ maps in Figure 9), the shear velocity pattern is coherent with 
the group velocity maps at $8 \mathrm{~s}$ (Figure 4). Thick sedimentary basins such as the Po plain, the Adriatic basin, the Alpine foreland or the Vienna basin, are associated with the lowest velocity anomalies.

At $32 \mathrm{~km}$ (Figure 9), our shear velocity map highlights variations in Moho depth (Figure 9). The low velocity anomalies in the Alps, Apennines and Dinarides correspond to the crustal roots of these orogens. Slow anomalies are also visible in the Anglo-Paris basin in the Northern part of France, in relation with the thick crust observed in this area (e.g. Laske et al. 2013). The low velocity signature of the Alpine crustal root is limited to the East by the Pannonian basin, where fast anomalies are observed. This is coherent with the presence of a rather thin crust in the Pannonian basin (e.g. Balázs et al. 2016). Stronger high velocity perturbations are associated with the Cenozoic rift system, from the Rhine graben to South-Eastern France, where the crust is thinner (e.g. Molinari \& Morelli 2011).

At $50 \mathrm{~km}$ depth, our model shows high velocity perturbations related to the Adriatic slab subducting under the Apennines (Figure 10). Beneath the Alps, the deep crustal root associated with low velocities is still visible, although it is interrupted by a fast anomaly under the Central Alps. This difference is due to the deeper Moho beneath the Alps than beneath the Apennines (Spada et al. 2013). The slab beneath the Apennines is delimited to the West by a sharp transition to slow anomalies associated with the shallow mantle under the stretched crusts of the Liguro-Provencal basin and the Tyrrhenian sea. A slab gap, which was documented by teleseismic traveltime tomography (Lucente et al. 1999; Giacomuzzi et al. 2011), is observed in the Southern part of the Apennines. It is also visible on profile EE' (Figure 11) where the fast anomaly associated with the slab is weaker between 500 and $600 \mathrm{~km}$ on the horizontal scale.

At $70 \mathrm{~km}$ depth (Figure 10), the high velocity anomaly associated with the slab shifts to the West, in agreement with the southwestward dip of the Adriatic subduction. On cross-section BB' (Figure 11), high velocity anomalies are observed in the mantle below the Apenninic front that clearly display the Adriatic slab plunging towards the South-West down to $100 \mathrm{~km}$ depth. The slab is however not visible on profiles CC' and DD' at depths larger than $\sim 60 \mathrm{~km}$.

Another noticeable feature of the velocity maps is the low velocity anomaly associated with the Eifel volcanic region. This anomaly is observed at 50 and $70 \mathrm{~km}$ (Figure 10) but not at shallower depths (Figure 9), in agreement with our group velocity observations. This is coherent with the presence of a shallow LAB reaching 40-50 km depth (e.g. Mathar et al. 2006; Seiberlich et al. 2013) due to an asthenospheric plume (e.g. Ritter et al. 2001; Keyser et al. 
2002; Pilidou et al. 2005) spreading at the bottom of an unusually hot lithosphere (Schintgen et al. 2015).

\subsection{Anisotropic structure}

As opposed to previous studies where radial anisotropy is observed in all parts of the study area (e.g. Zhu et al. 2015), the major part of our posterior median model is isotropic. It only exhibits radial anisotropy in some localized areas of the crust and uppermost mantle. The most striking pattern of anisotropy is observed from about 20 to $40 \mathrm{~km}$ depth along the Apennines, from the Northern part of the chain to the Calabrian arc (see maps at 26 and $32 \mathrm{~km}$ depth in Figure 11 and Figure 9 respectively). The observation of positive radial anisotropy with $V_{S H} / V_{S V} \approx 1.2$ is associated with a probability larger than $85 \%$ and is therefore considered as robust (i.e. $85 \%$ of the sampled models in the ensemble solution have positive radial anisotropy). The cross-sections across and along the chain (Figure 11) clearly suggest that this positive radial anisotropy anomaly is restricted to the lower crust. Given the synthetic tests shown in Figure 8, such a high value of $V_{S H} / V_{S V}$ cannot result from isotropic hectometric layering in the lower crust. In the underlying mantle, negative $\left(V_{S H}<V_{S V}\right)$ anisotropy is observed with a high probability from $\sim 60$ to $\sim 100 \mathrm{~km}$ depth (Figure 11). This anomaly coincides with the high velocity perturbation interpreted as the Adriatic slab.

Another robust anisotropy pattern, although corresponding to a much smaller area, is observed on the 32-km depth slices beneath the westernmost Po basin (IB in Figure 9) and on the CIFALPS profile (at $\sim 220 \mathrm{~km}$ distance in Figure 12). On these figures, a negative anisotropy anomaly $\left(V_{S V}>V_{S H}\right)$ is associated with the high $V_{S V}$ anomaly attributed to the Ivrea Body. The Ivrea body (IB) is a high-velocity high-density body located at depths $\geq 10 \mathrm{~km}$ in the crust of the Western Alps, which is interpreted as a flake of Adriatic upper mantle (Closs \& Labrouste 1963; Nicolas et al. 1990). To our knowledge, this is the first time that a strong anisotropie signature is associated with the Ivrea body. 
Figure 11: 2-D cross-sections along four profiles in the Apennines. Locations of the profiles BB' to EE' are displayed on the map of radial anisotropy at $26 \mathrm{~km}$ depth, in the bottom left corner of the figure. AA' cross-section corresponds to the CIFALPS profile (Zhao et al. 2015) and is represented in Figure 12. For each profile, the top panel displays absolute velocities in the crust and perturbations of velocity in the mantle. The middle and bottom panels display radial anisotropy as $V_{S H} / V_{S V}$ and the probability of anisotropy respectively. Moho depth (solid black line on each profile) is defined as the iso-velocity $4.2 \mathrm{~km} / \mathrm{s}$, as in PREM (Dziewoński \& Anderson 1981). IB: Ivrea body. 

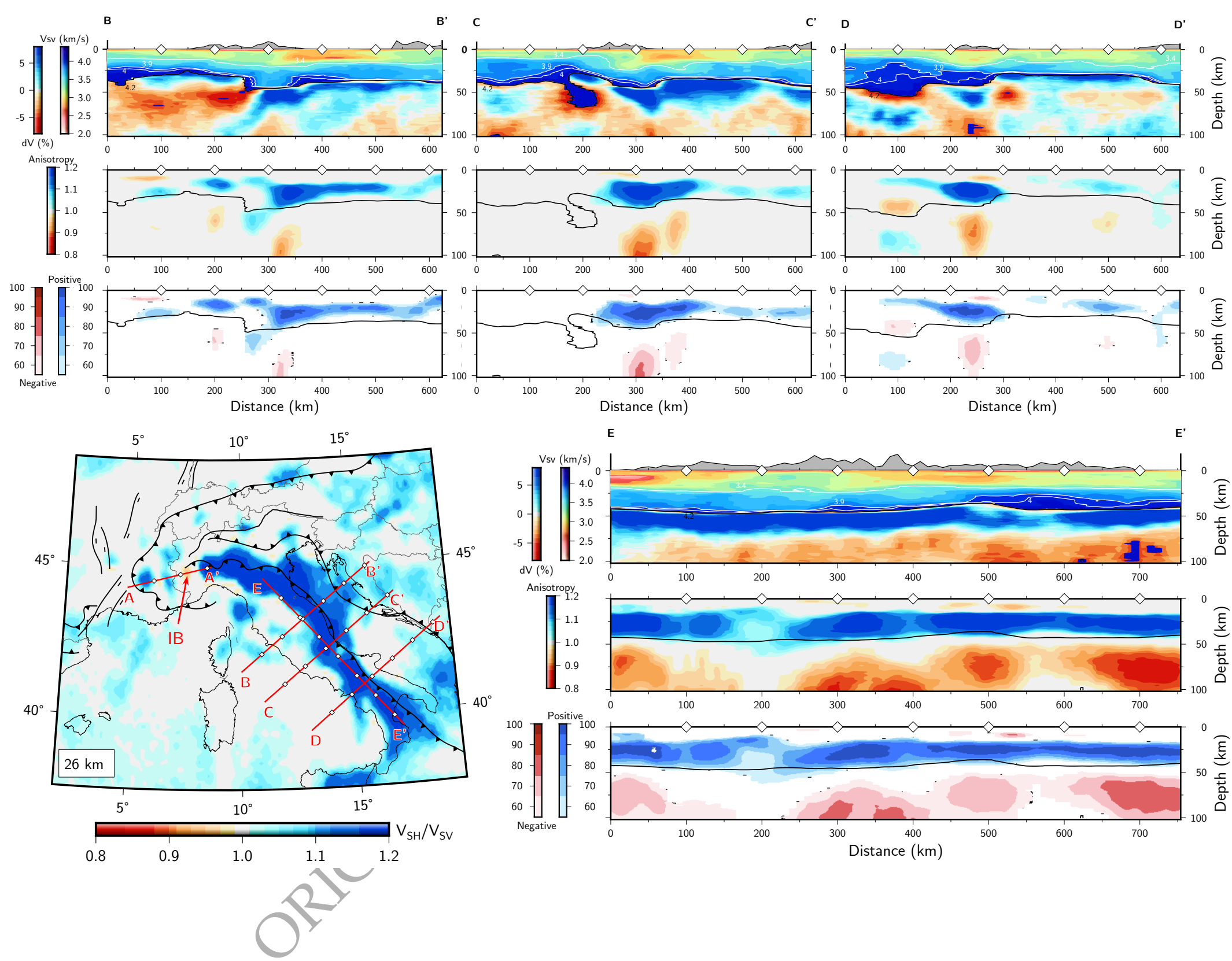


\section{DISCUSSION}

\subsection{Comparison with previous studies}

Our 3-D shear wave velocity model is in good agreement with recent high resolution ambient noise tomography studies (Kästle et al. 2018; Lu et al. 2018, 2020) that show similar largescale structures in the crust and uppermost mantle. Even though the spatial resolution of our model does not reach that of these previous models, some features are well imaged, such as the Adriatic slab under the Apennines.

The most original contribution of this study comes from the radial anisotropy model. Our most striking result is that radial anisotropy is clearly localized and not pervasive in the crust and upper mantle. This observation contrasts with previous studies (Kustowski et al. 2008; Boschi et al. 2009; Schivardi \& Morelli 2011; Zhu et al. 2015) where radial shear wave anisotropy is required everywhere at crustal and mantle depths in Europe to explain the observed Love/Rayleigh discrepancy. One of the origins for this difference may be the unequal data coverage between Rayleigh and Love waves in these studies, but it most likely arises from the fact that we use a massive dataset that includes short period measurements (down to $5 \mathrm{~s}$ ) combined with a Bayesian inversion that efficiently accounts for possible layering, as shown by our synthetic tests in Figure 8. In previous studies based on optimization schemes, the level of vertical smoothness is fixed in advance, and the solution represents the best fitting model given the imposed parameterization. By introducing anisotropy as a free parameter, seismic data can be fitted with smoother models and fewer spatial parameters (Montagner \& Jobert 1988; Trampert \& Woodhouse 2003). A heterogeneous isotropic medium may then be imaged as a smooth anisotropic model. In the transdimensional scheme used here, no vertical scale is imposed, as neither the level oflayering nor the presence of anisotropy is determined in advance. Although the first step of our tomographic inversion involves a standard least squares approach with a level of lateral smoothing determined by the horizontal correlation length $L_{\text {corr }}$, radialanisotropy is involved only in the second step, where we invert the group velocity maps for the $3-\mathrm{D}$ model. As this stage, the transdimensional inversion is free to choose between layering and radial anisotropy, while respecting the parsimonious condition where simple models described by fewer parameters are favoured. For this reason, the existence and level of radial anisotropy is directly determined by the data and not by a selected degree of smoothing.

At each geographical point, the posterior distribution of layered models obtained after our 1-D transdimensional Bayesian inversion exhibits models with many isotropic layers (resulting in 


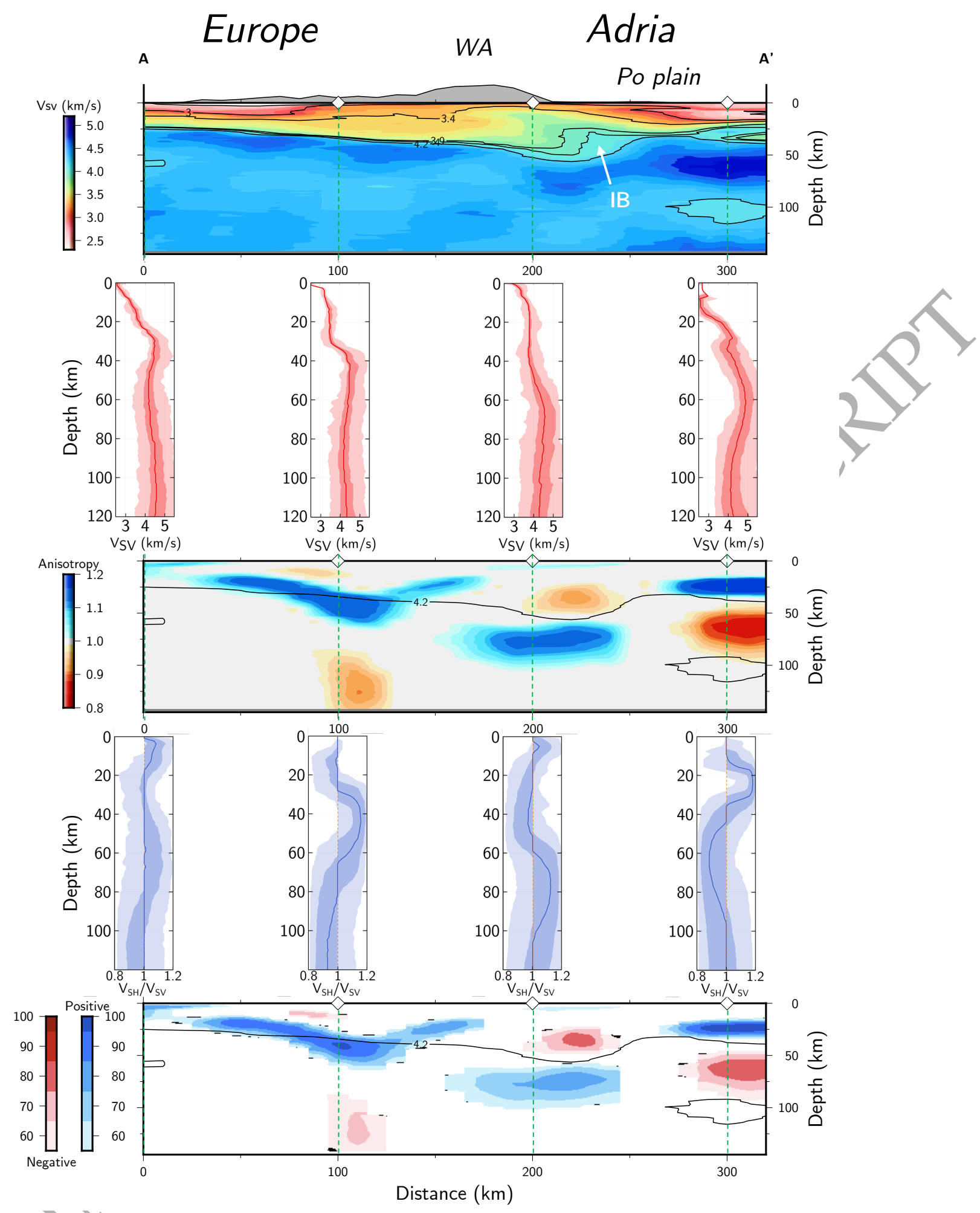

Figure 12. 2-D cross-sections along the CIFALPS profile (AA' in Figure 11) and posterior distributions of velocity (red 1-D profiles) and radial anisotropy (blue 1-D profiles) as described in Figure 6 for four points along the profile. Top panel: absolute velocity; middle panel: radial anisotropy as $V_{S H} / V_{S V}$; bottom panel: probability of positive (blue) and negative (red) radial anisotropy. IB: Ivrea Body ; WA: Western Alps 
a median $V_{S H} / V_{S V}$ value of 1). Our model then suggests that the Rayleigh/Love discrepancy observed in the data can be explained by small scale (hectometric) layering in the crust and uppermost mantle in most of Europe, except in the Apennines. Such small-scale layering is likely to be present in the lower crust of Variscan Europe, as imaged by deep reflection seismics, and it could result from layering of mafic/ultramafic intrusions of partial melts derived from the upper mantle (Singh \& McKenzie 1993; Rey 1993). Our synthetic tests (Figure 8) suggest that thin layering with up to $30 \%$ velocity contrasts would not be mapped as anisotropy with our inversion. This suggests that when accounting for possible layering, radial anisotropy is not necessarily required to reconcile Love and Rayleigh observations beneath most of Europe.

\subsection{A focus on the Apennines}

The Adriatic slab is rather well imaged in our model under the Apennines (Figure 10). Previous studies report a very steep angle of subduction towards the West in the Northern Apennines (Koulakov et al. 2009; Kästle et al. 2018; Zhao et al. 2016a). Our model rather shows a slab subducting towards the West with a moderate angle (profile BB' Figure 10). The slab gap observed in the Southern Apennines is consistent with the gap previously reported by e.g. Piromallo \& Morelli (2003); Koulakov et al. (2009) from body wave tomography and by Kästle et al. (2018) from surface wave tomography. As suggested by Carminati \& Doglioni (2012), its existence could be related to different convergence rates between Northern and Southern Apennines.

Strong positive radial anisotropy is observed with a high probability in the lower crust of the chain. We show in Figure 8 that this high level of anisotropy cannot be ascribed to thin layering as described e.g. in Singh \& McKenzie (1993). Our results rather suggest the horizontal alignment of the fast axes of anisotropic minerals such as amphiboles and micas (see Almqvist \& Mainprice 2017, for a review on anisotropy in the continental crust). We propose that this lattice preferred orientation of minerals is related to horizontal ductile flow in the lower crust of the Apennines in response to the recent and present-day extensional regime observed in the chain from structural, seismotectonic and GPS data (e.g. D'Agostino et al. 2008) and caused by the subduction of Adria both under the Apennines and Dinarides. In the upper mantle, anisotropy is commonly associated with the orientation of fast axes of olivine crystals, as olivine is the dominant mineral in the mantle. A negative radial anisotropy in the sublithospheric mantle suggests vertical flow (Montagner 1994). Negative radial anisotropy is observed at sublithospheric mantle depths beneath the Apennines, under 
the slab. It suggests sub-vertical orientation of olivine fast axes, likely related to the westward dipping slab.

\subsection{Anisotropy along the CIFALPS profile}

Along the CIFALPS profile (AA' profile in Figure 12), the European Moho reaches $50 \mathrm{~km}$ depth under the Ivrea body (Figure 12), while Zhao et al. (2015) from a receiver function study, and Zhao et al. (2020) from a surface wave ambient noise study have documented a deeper Moho depth of 70-75 km in a very localized zone (<50 km in width). Zhao et al. (2020) applied a transdimensional Bayesian inversion scheme similar to ours but in the inversion of Rayleigh wave group velocity data for a 3 -D isotropic $V_{S V}$ model. The differences between our and their $V_{S V}$ image can be explained by our selection procedure, where we imposed an equal coverage between Love and Rayleigh measurements, thus resulting in a decrease of Rayleigh wave measurements compared to recent isotropic studies. It is therefore likely that we do not resolve the small area where the Moho exceeds $50 \mathrm{~km}$ depth.

In the Ivrea body high $V_{S V}$ anomaly, we observe negative radial anisotropy $\left(V_{S V}>V_{S H}\right)$ at $25-50 \mathrm{~km}$ depth along the CIFALPS profile (Figure 12). The anisotropy map at 32-km depth (Figure 9) shows that the anisotropy anomaly does not follow the North-South extension of the Ivrea body documented by its positive Bouguer anomaly (Masson et al. 1999). It rather appears as a small anisotropic spot inside a mostly isotropic body. Despite its small size, the anisotropy anomaly is reliable as documented by its high probability (Figure 9). Therefore, we propose that it is related to the presence of highly-anisotropic serpentinites in the Ivrea body and/or in the subduction complex beneath it, with strongly-dipping fast-velocity directions (Solarino et al. 2018; Zhao et al. 2020). This interpretation should be valid for the entire Ivrea body, including the parts that appear isotropic to the North and South of the CIFALPS profile. A possible explanation for the absence of anomaly is the resolution of our tomography, which may be insufficient to image such a narrow body ( $\sim 50-70 \mathrm{~km}$ wide). Another interpretation would be to link the negative anisotropy to the set of sub-vertical faults that produce numerous microearthquakes at 20-75 km depth beneath the Westernmost Po plain, precisely at the same location as the anisotropy spot (Malusà et al. 2017). This interpretation would explain why other parts of the Ivrea body appear isotropic, as no anomalously deep earthquakes are recorded there.

The pattern of positive radial anisotropy in the upper mantle under the Ivrea body, from 55 to $100 \mathrm{~km}$ depth suggests the presence of frozen-in anisotropy (e.g. Yuan \& Romanowicz 2010) in the lithosphere, due to past deformation. The same interpretation can be applied to 
the positive anisotropy observed at Moho depth under Europe. This would however require further investigation.

\section{CONCLUSIONS}

We present the first 3-D radially anisotropic probabilistic model of the crust and uppermost mantle of Western Europe with a lateral resolution of a few tens of kilometers. This model is derived from Rayleigh and Love waves group velocity measurements in the period range 5 to $149 \mathrm{~s}$. The dispersion data are obtained from the correlation of ambient noise at more than 700,000 station pairs in Europe. The collection of such a large dataset, which is a difficult task in particular for Love wave data derived from horizontal components of ambient noise records, has been made possible by the recent deployment of the AlpArray temporary seismic network (Hetényi et al. 2018).

We acknowledge here that a number of approximations have been made to $/$ construct this $3-\mathrm{D}$ model, that may result in a number of errors and biases:

(i) sources of noise are not uniformly distributed, which results in an approximate reconstruction of Green's functions from ambient noise correlation.

(ii) azimuthal variations of group velocities were ignored in the 2-D inversion. These unmapped azimuthal variations can result in biased group velocity maps.

(iii) Love and Rayleigh waves are measured on different components, and their measurements may be contaminated by different contributions. Although we have ensured that we have similar data coverage, these different levels of error may have resulted in different lateral resolutions between Love and Rayleigh group velocity maps, and thus producing some apparent isotropic or anisotropic heterogeneities.

(iv) the Bayesian inversion of dispersion curves was done assuming a radially symmetric Earth, and group velocitíes were computed by normal mode summation. That is, dispersion curves were assumed to be only sensitive to the 1-D structure below the considered point, and 3-D structural effects have been ignored.

(v) a discontinuous reference model was imposed as the mean of the prior distribution. Our results shown here depend on this chosen reference model.

However, the large-scale structures of our 3-D shear wave velocity model are in good agreement with studies conducted in the same region from Rayleigh wave dispersion data (e.g. Kästle et al. 2018; Lu et al. 2018, 2020; Zhao et al. 2020). The main outcome of our work concerns the pattern of radial anisotropy, which is present only in restricted areas of our model. This is 
in stark contrast to previous large scale studies that showed radial anisotropy throughout the crust and upper mantle (Kustowski et al. 2008; Boschi et al. 2009; Schivardi \& Morelli 2011; Zhu et al. 2015). We attribute this difference to the thin hectometric layering of the lower crust, which is ubiquitous in the Variscan crust of Western Europe and can be mapped as radial anisotropy in large-scale tomographic models. Our Bayesian inversion applied to a very large dataset, including short period measurements down to $5 \mathrm{~s}$, produces radial anisotropy in a more parsimonious way, only in locations where it is required by data. Our synthetic tests demonstrate that the transdimensional inversion does not introduce artificial radial anisotropy in the model, even when strong layering is present.

Our most prominent and robust observation is positive radial anisotropy $\left(V_{S H}>V_{S V}\right)$ in the lower crust of the Apennines. We attribute this to horizontal flow in the ductile lower crust in response to the recent and present-day extension observed from structural geology, earthquake focal mechanisms and geodesy.

In order to improve the model, future work may involve the use of higher frequency data such as converted or reflected body waves, in a joint inversion with surface wave measurements. Indeed, higher frequency content would allow to retrieve the depth of seismic discontinuities thus avoiding the need of a reference velocity model in the inversion at depth.

Dense temporary networks similar to AlpArray are expected to be deployed in Europe in the coming years (e.g. AdriaArray). Applying the same procedure we used to a larger surface waves dataset combining measurements obtained from those different arrays would highly improve the resolution of radially anisotropic models in Europe.

\section{AVAILABILITY OF THE MODEL AND CODES}

Our tomographic model and the Bayesian inversion code are available on request to Chloé Alder. The regionalization code is available on request to Eric Debayle.

\section{ACKNOWLEDGEMENTS}

The authors thank two anonymous reviewers for their valuable comments on the manuscript. This work was funded by the European Union's Horizon 2020 research and innovation program under Grant Agreement 716542. It is part of the AlpArray-FR project funded by Agence Nationale de la Recherche (contract ANR-15-CE31-0015). The authors thank the AlpArray Seismic Network Team: György HETÉNYI, Rafael ABREU, Ivo ALLEGRETTI, MariaTheresia APOLONER, Coralie AUBERT, Simon BESANÇON, Maxime BÈS DE BERC, Götz 
BOKELMANN, Didier BRUnel, Marco CAPELlO, Martina ČARMAN, Adriano CAVALIERE, Jérôme CHÈzE, Claudio CHIARABBA, John CLINTON, Glenn COUGOULAT, Wayne C. CRAWFORD, Luigia CRISTIANO, Tibor CZIFRA, Ezio D'ALEMA, Stefania DANESI, Romuald DANIEL, Anke DANNOWSKI, Iva DASOVIĆ, Anne DESCHAMPS, Jean-Xavier DESSA, Cécile DOUBRE, Sven EGDORF, ETHZ-SED Electronics Lab, Tomislav FIKET, Kasper FISCHER, Wolfgang FRIEDERICH, Florian FUCHS, Sigward FUNKE, Domenico GIARDINI, Aladino GOVONI, Zoltán GRÁCZER, Gidera GRÖSCHL, Stefan HEIMERS, Ben HEIT, Davorka HERAK, Marijan HERAK, Johann HUBER, Dejan JARIĆ, Petr JEDLIČKA, Yan JIA, Hélène JUND, Edi KISSLING, Stefan KLINGEN, Bernhard KLOTZ, Petr KOLÍNSKÝ, Heidrun KOPP, Michael KORN, Josef KOTEK, Lothar KÜHNE, Krešo KUK, Dietrich LANGE, Jürgen LOOS, Sara LOVATI, Deny MALENGROS, Lucia MARGHERITI, Christophe MARON, Xavier MARTIN, Marco MASSA, Francesco MAZZARINI, Thomas MEIER, Laurent MÉTRAL, Irene MOLINARI, Milena MORETTI, Helena MUNZAROVÁ, Anna NARDI, Jurij PAHOR, Anne PAUL, Catherine PÉQUEGNAT, Daniel PETERSEN, Damiano PESARESI, Davide RICCININI, Claudia PIROMALlO, Thomas PLENEFISCH, Jaroslava PLOMEROVÁ, Silvia PONDRELLI, Snježan PREVOLnIK, Roman RACINE, Marc RÉGNIER, Miriam REISS, Joachim RITTER, Georg RÜMPKER, Simone SALIMBENI, Marco SANTULIN, Werner SCHERER, Sven SCHIPPKUS, Detlef SCHULTE-KORTNACK, Vesna SIPKA, Stefano SOLARINO, Daniele SPALLAROSSA, Kathrin SPIEKER, Josip STIPČ́EVIĆ, Angelo STROLLO, Bálint SÜLE, Gyöngyvér SZANYI, Eszter SZÜCS, Christine THØMAS, Martin THORWART, Frederik TILMANN, Stefan UEDING, Massimiliano VALLOCCHIA, Luděk VECSEY, René VOIGT, Joachim WASSERMANN, Zoltán WEBER, Christian WEIDLE, Viktor WESZTERGOM, Gauthier WEYLAND, Stefan WłEMER, Felix WOLF, David WOLYNIEC, Thomas ZIEKE, Mladen ŽIVČIĆ

\section{REFERENCES}

Albuquerque<Seismological Laboratory (ASL)/USGS, 1988. Global Seismograph Network (GSN IRIS/USGS).

Alder, C., Bodin, T., Ricard, Y., Capdeville, Y., Debayle, E., \& Montagner, J.-P., 2017. Quantifying seismic anisotropy induced by small-scale chemical heterogeneities, Geophysical Journal International, 211(3), 1585-1600.

Almqvist, B. S. \& Mainprice, D., 2017. Seismic properties and anisotropy of the continental crust: Predictions based on mineral texture and rock microstructure, Rev. Geophys., 55(2), 367-433. 
AlpArray Seismic Network, 2014. Eastern Alpine Seismic Investigation (EASI) - AlpArray Complimentary Experiment.

AlpArray Seismic Network, 2015. AlpArray Seismic Network (AASN) temporary component.

Aristotle University Of Thessaloniki Seismological Network, 1981. Permanent Regional Seismological Network operated by the Aristotle University of Thessaloniki.

Aster, R. C., Borchers, B., \& Thurber, C. H., 2018. Parameter estimation and inverse problems, Elsevier.

Backus, G. E., 1962. Long-wave elastic anisotropy produced by horizontal layering, J. Geophys. Res., 67(11), 4427-4440.

Balázs, A., Matenco, L., Magyar, I., Horváth, F., \& Cloetingh, S., 2016. The link between tectonics and sedimentation in back-arc basins: New genetic constraints from the analysis of the Pannonian Basin, Tectonics, 35(6), 1526-1559.

Barruol, G., Deschamps, A., \& Coutant, O., 2004. Mapping upper mantle anisotropy beneath SE France by SKS splitting indicates Neogene asthenospheric flow induced by Apenninic slab roll-back and deflected by the deep Alpine roots, Tectonophysics, 394(1-2), 125-138.

Barruol, G., Bonnin, M., Pedersen, H., Bokelmann, G. H., \& Tiberi, C., 2011. Belt-parallel mantle flow beneath a halted continental collision: The Western Alps, Earth Planet. Sci. Lett., 302(3-4), $429-438$.

Birch, F., 1961. The Velocity of Compressional Waves in Rocks to 10 Kilobars, Part 2, J. Geophys. Res., 66(7), 2199-2224.

Bodin, T., Sambridge, M., Rawlinson, N., \& Arroucau, P., 2012a. Transdimensional tomography with unknown data noise, Geophys. J. Int., 189(3), 1536-1556.

Bodin, T., Sambridge, M., Tkalćić, H., Arroucau, S., Gallagher, K., \& Rawlinson, N., 2012b. Transdimensional inversion of receiver functions and surface wave dispersion, J. Geophys. Res. Solid Earth, $\mathbf{1 1 7}(2), 1-24$.

Bodin, T., Capdeville, Y., Romanowicz.,B., \& Montagner, J.-P., 2015. Interpreting radial anisotropy in global and regional tomographic models, in The Earth's Heterogeneous Mantle, chap. 4, pp. 105-144, eds Khan, A. \& Deschamps, F., Springer International Publishing.

Bodin, T., Leiva, J., Romanowicz, B., Maupin, V., \& Yuan, H., 2016. Imaging anisotropic layering with Bayesian inversion of multiple data types, Geophys. J. Int., 206(1), 605-629.

Bogazici University Kandilli Observatory And Earthquake Research Institute, 2001. Bogazici University Kandilli Observatory And Earthquake Research Institute.

Bokelmann, G., Qorbani, E., \& Bianchi, I., 2013. Seismic anisotropy and large-scale deformation of the Eastern Alps, Earth Planet. Sci. Lett., 383, 1-6.

Boschi, L., Ekström, G., \& Kustowski, B., 2004. Multiple resolution surface wave tomography: the Mediterranean basin, Geophysical Journal International, 157(1), 293-304.

Boschi, L., Fry, B., Ekström, G., \& Giardini, D., 2009. The European upper mantle as seen by surface 
waves, Surv. Geophys., 30(4-5), 463-501.

Bozdağ, E. \& Trampert, J., 2008. On crustal corrections in surface wave tomography., Geophys. J. Int., 172(3), 1066-1082.

Carminati, E. \& Doglioni, C., 2012. Alps vs. Apennines: the paradigm of a tectonically asymmetric Earth, Earth-Science Reviews, 112(1-2), 67-96.

Chaljub, E., 2017. Saint-Guérin Arch Dam Experiment.

Chang, S.-J. \& Ferreira, A. M. G., 2017. Improving global radial anisotropy tomography: The importance of simultaneously inverting for crustal and mantle structure., Bull. seism. Soc. Am., 107(2), $624-638$.

Chevrot, S., Sylvander, M., \& RESIF, 2017. Seismic network X7: PYROPE PYRenean Observational Portable Experiment (RESIF-SISMOB).

Chevrot, S., Diaz, J., Sylvander, M., Ruiz, M., \& RESIF, 2018. Seismic network ZU: Orogen-X temporary experiment (RESIF-SISMOB).

Chiarabba, C. \& Amato, A., 1996. Crustal velocity structure of the Apennines (Italy) from P-wave travel time tomography, Ann. di Geofis., 39(6), 1133-1148.

Chiarabba, C., De Gori, P., \& Speranza, F., 2009. Deep geometry and rheology of an orogenic wedge developing above a continental subduction zone: Seismological evidence from the northern-central Apennines (Italy), Lithosphere, 1(2), 95-104.

Closs, H. \& Labrouste, Y., 1963. Recherches séismologiques dans les Alpes Occidentales au moyen des grandes explosions en 1956, 1958 et 1960: Année Géophysique Internationale, CNRS.

Corinth Rift Laboratory Team And RESIF Datacenter, 2013. CL - Corinth Rift Laboratory Seismological Network (CRLNET).

D’Agostino, N., Avallone, A., Cheloni, D., D'Anastasio, E., Mantenuto, S., \& Selvaggi, G., 2008. Active tectonics of the Adriatic region from GPS and earthquake slip vectors, J. Geophys. Res. Solid Earth, 113(12), 1-19.

DANA, 2012. Dense Array for North Anatolia.

Debayle, E. \& Kennett, B. L. N., 2000. Anisotropy in the Australian upper mantle from Love and Rayleigh waveform inversion, Earth Planet. Sci. Lett., 184, 339-351.

Debayle, E. \& Ricard, Y., 2012. A global shear velocity model of the upper mantle from fundamental and higher rayleigh mode measurements, Journal of Geophysical Research: Solid Earth, 117(B10).

Debayle, E. \& Sambridge, M., 2004. Inversion of massive surface wave data sets: Model construction and resolution assessment, J. Geophys. Res., 109(B2), B002652.

Debayle, E., Dubuffet, F., \& Durand, S., 2016. An automatically updated S -wave model of the upper mantle and the depth extent of azimuthal anisotropy, Geophys. Res. Lett., 43(2), 674-682.

Department Of Earth And Environmental Sciences, Geophysical Observatory, University Of Munchen, 2001. BayernNetz.

Deschamps, A. \& Beucler, E., 2013. POSA experiment. 
Di Stefano, R., Kissling, E., Chiarabba, C., Amato, A., \& Giardini, D., 2009. Shallow subduction beneath Italy: Three-dimensional images of the Adriatic-European-Tyrrhenian lithosphere system based on high-quality P wave arrival times, J. Geophys. Res. Solid Earth, 114(5), 1-17.

Dias, N., Silveira, G., \& Haberland, C., 2010. Data of the temporary seismic WILAS network.

Disaster And Emergency Management Presidency (AFAD Turkey), 1990. National Seismic Network of Turkey (AFAD).

Dziewoński, A. \& Anderson, D. L., 1981. Preliminary reference Earth model, Phys. Earth Planet. Inter., 25(4), 297-356.

Dziewonski, A., Bloch, S., \& Landisman, M., 1969. A technique for the analysis of transient seismic signals, Bulletin of the seismological Society of America, 59(1), 427-444.

Earth Science Institute Of The Slovak Academy Of Sciences (ESISAS), 2004. National Network of Seismic Stations of Slovakia.

Faccenna, C., Becker, T. W., Auer, L., Billi, A., Boschi, L., Brun, J. P., Capitanio, F. A., Funiciello, F., Horvàth, F., Jolivet, L., Piromallo, C., Royden, L., Rossetti, F., \& Serpelloni, E., 2014. Mantle dynamics in the Mediterranean, Rev. Geophys., 52(3), 283-332.

Federal Institute for Geosciences and Natural Resources (BGR), 1976. German Regional Seismic Network (GRSN).

Fichtner, A., Kennett, B. L., Igel, H., \& Bunge, H.-P., 2010. Full waveform tomography for radially anisotropic structure: new insights into present and past states of the australasian upper mantle, Earth and Planetary Science Letters, 290(3-4), 270-280.

Forsyth, D. W., 1975. The Early Structural Evolution and Anisotropy of the Oceanic Upper Mantle, Geophys. J. R. Astron. Soc., 43(1), 103-162.

French Landslide Observatory - Seismological Datacenter / RESIF, 2006. Observatoire Multidisciplinaire des Instabilités de Versants (OMIV).

Fry, B., Deschamps, F., Kissling, E., Stehly, L., \& Giardini, D., 2010. Layered azimuthal anisotropy of Rayleigh wave phase velocities in the European Alpine lithosphere inferred from ambient noise, Earth Planet. Sci. Lett., 297(1-2), 95-102.

GEOFON Data Centre, 1993. GEOFON Seismic Network.

Geological And Seismological Institute Of Moldova, 2007. Moldova Digital Seismic Network.

Geological Survey Départment Cyprus, 2013. Cyprus Broadband Seismological Network.

Geological Survey-Provincia Autonoma Di Trento, 1981. Trentino Seismic Network.

Giacomuzzi, G., Chiarabba, C., \& De Gori, P., 2011. Linking the Alps and Apennines subduction systems: New constraints revealed by high-resolution teleseismic tomography, Earth Planet. Sci. Lett., 301(3-4), 531-543.

Green, P. J., 1995. Reversible jump Markov chain Monte Carlo computation and Bayesian model determination, Biometrika, 82(4), 711-732.

Guéguen, P., Coutant, O., Langlais, M., \& RESIF, 2017. Maurienne Seismic Swarm 2017-2018. 
Handy, M. R., M. Schmid, S., Bousquet, R., Kissling, E., \& Bernoulli, D., 2010. Reconciling platetectonic reconstructions of Alpine Tethys with the geological-geophysical record of spreading and subduction in the Alps, Earth-Science Rev., 102(3-4), 121-158.

Heit, B., Yuan, X., \& Mancilla, F. D. L., 2010. High Resolution Seismological Profiling across Sierra Nevada (HIRE).

Heit, B., Weber, M., Tilmann, F., Haberland, C., Jia, Y., Carraro, C., Walcher, G., Franceschini, A., \& Pesaresi, D., 2017. The Swath-D Seismic Network in Italy and Austria.

Herrmann, R. B., 1973. Some aspects of band-pass filtering of surface waves, Bull. Seismol. Soc. Am., 63(2), 663-671.

Hetényi, G., Molinari, I., Clinton, J., Bokelmann, G., Bondár, I., Crawford, W. C., Dessa, J.-X. Doubre, C., Friederich, W., Fuchs, F., Giardini, D., Gráczer, Z., Handy, M. R., Herak, M., Jia, Y. Kissling, E., Kopp, H., Korn, M., Margheriti, L., Meier, T., Mucciarelli, M., Paul, A., Pesaresi, D., Piromallo, C., Plenefisch, T., Plomerová, J., Ritter, J., Rümpker, G., Šipka, V., Spallarossa, D., Thomas, C., Tilmann, F., Wassermann, J., Weber, M., Wéber, Z., Wesztergom, V.,Zivcíć, M., AlpArray Seismic Network Team, Abreu, R., Allegretti, I., Apoloner, M.-T., Aubert, C., Besançon, S., Bès de Berc, M., Brunel, D., Capello, M., Čarman, M., Cavaliere, A., Chèze, J., Chiarabba, C., Cougoulat, G., Cristiano, L., Czifra, T., D’Alema, E., Danesi, S., Daniel, R., Dannowski, A., Dasović, I., Deschamps, A., Egdorf, S., ETHZ-SED Electronics Lab, Fiket, T., Fischer, K., Funke, S., Govoni, A., Gröschl, G., Heimers, S., Heit, B., Herak, D., Huber, J., Jarić, D., Jedlička, P., Jund, H., Klingen, S., Klotz, B., Kolínský, P., Kotek, J., Kühne, L., Kuk, K., Lange, D., Loos, J., Lovati, S., Malengros, D., Maron, C., Martin, X., Massa, M., Mazzarini, F., Métral, L., Moretti, M., Munzarová, H., Nardi, A., Pahor, J., Péquegnat, C., Petersen, F., Piccinini, D., Pondrelli, S., Prevolnik, S., Racine, R., Régnier, M., Reiss, M, Salimbeni, S., Santulin, M., Scherer, W., Schippkus, S., Schulte-Kortnack, D., Solarino, S., Spieker, K., Stipčević, J., Strollo, A., Süle, B., Szanyi, G., Szűcs, E., Thorwart, M., Ueding, S., Vallocchia, M., Vecsey, L., Voigt, R., Weidle, C., Weyland, G., Wiemer, S., Wolf, F., Wolyniec, D., Zieke, T., AlpArray OBS Cruise Crew, \& AlpArray Working Group, 2018. The AlpArray Seismic Network: A Large-Scale European Experiment to Image the Alpine Orogen, Surveys in Geophysics, 39(5), 1009-1033.

INGV Seismological Datá Centre, 1997. Rete Sismica Nazionale (RSN).

INSN, 1993. Irish Nátional Seismic Network, operated by the Dublin Institute for Advanced Studies and supported by the Geological Survey Ireland.

Institut Cartógràfic I' Geològic De Catalunya, 1984. Catalan Seismic Network.

Institut De Physique Du Globe De Paris (IPGP) \& (EOST), E. E. O. D. S. D. L. T. D. S., 1982.

GEOSCOPE, French Global Network of broad band seismic stations.

Institute Earth Sciences "Jaume Almera" CSIC (ICTJA Spain), 2007. IberArray.

Institute Of Geophysics, A. O. S. O. T. C. R., 1973. Czech Regional Seismic Network.

Institute Of Geosciences, Energy, Water And Environment, 2002. Albanian Seismological Network. 
Institute Of Seismology, University Of Helsinki, 1980. The Finnish National Seismic Network.

Instituto Dom Luiz (IDL)-Faculdade De Ciências Da Universidade De Lisboa, 2003. University of

Lisbon Seismic Network.

Instituto Geografico Nacional, Spain, 1999. Spanish Digital Seismic Network.

Instituto Português Do Mar E Da Atmosfera, I.P., 2006. Portuguese National Seismic Network.

Jena, Friedrich Schiller University, 2009. Thüringer Seismologisches Netz (TSN).

Kästle, E. D., Soomro, R., Weemstra, C., Boschi, L., \& Meier, T., 2016. Two-receiver measurements of phase velocity: Cross-validation of ambient-noise and earthquake-based observations, Geophys. J. Int., 207(3), 1493-1512.

Kästle, E. D., El-Sharkawy, A., Boschi, L., Meier, T., Rosenberg, C., Bellahsen, N., Cristiano, L. \& Weidle, C., 2018. Surface Wave Tomography of the Alps Using Ambient-Noise and Earthquake Phase Velocity Measurements, J. Geophys. Res. Solid Earth, 123(2), 1770-1792.

Keyser, M., Ritter, J. R., \& Jordan, M., 2002. 3D shear-wave velocity structure of the Eifel plume, Germany, Earth and Planetary Science Letters, 203(1), 59-82.

Koulakov, I., Kaban, M. K., Tesauro, M., \& Cloetingh, S., 2009. P- and S-velocity anomalies in the upper mantle beneath Europe from tomographic inversion of ISC data, Gếphys. J. Int., 179(1), $345-366$.

Kustowski, B., Ekström, G., \& Dziewoński, A. M., 2008. The shear-waye yelocity structure in the upper mantle beneath Eurasia, Geophys. J. Int., 174(3), 978-992.

Kövesligethy Radó Seismological Observatory (Geodetic And Geophysical Institute, Research Centre For Astronomy And Earth Sciences, Hungarian Academy Of Sciences (MTA CSFK GGI KRSZO)), 1992. Hungarian National Seismological Network.

Laboratorio Subterraneo De Canfranc, 2011. LSC (Laboratorio Subterraneo Canfranc).

Laske, G., Masters, G., Ma, Z., \& Pasyanos, M., 2013. Update on CRUST1.0 - A 1-degree global model of Earth's crust, in Geophys. Res. Abstr, vol. 15, p. 2658, EGU General Assembly Vienna, Austria.

Leipzig University, 2001. SXNET Saxon Seismic Network.

Lekić, V. \& Romanowicz, B., 2011. Inferring upper-mantle structure by full waveform tomography with the spectral element method, Geophysical Journal International, 185(2), 799-831.

Levshin, A. L., Yanơskaya, T., Lander, A. V., Bukchin, B. G., Barmin, M. P., Ratnikova, L., \& Its, E. N., 1989. Seismic surface waves in a laterally inhomogeneous Earth, Springer, Dordrecht.

Lippitsch, R., Kissling, E., \& Ansorge, J., 2003. Upper mantle structure beneath the Alpine orogen from high-resolution teleseismic tomography, J. Geophys. Res., 108(B8), 2376.

Lu, X., Stehly, L., \& Paul, A., 2018. High-resolution surface wave tomography of the European crust and uppermost mantle from ambient seismic noise, Geophys. J. Int., 214(2), 1136-1150.

Lu, Y., Stehly, L., Brossier, R., \& Paul, A., 2020. Imaging Alpine crust using ambient noise waveequation tomography, Geophys. J. Int., 222, 69-85. 
Lucente, F. P., Chiarabba, C., Cimini, G. B., \& Giardini, D., 1999. Tomographic constraints on the geodynamic evolution of the Italian region, Journal of Geophysical Research: Solid Earth, 104(B9), 20307-20327.

Lucente, F. P., Margheriti, L., Piromallo, C., \& Barruol, G., 2006. Seismic anisotropy reveals the long route of the slab through the western-central Mediterranean mantle, Earth and Planetary Science Letters, 241(3-4), 517-529.

Malinverno, A. \& Briggs, V. A., 2004. Expanded uncertainty quantification in inverse problems: Hierarchical Bayes and empirical Bayes, Geophysics, 69(4), 1005-1016.

Malusà, M. G., Zhao, L., Eva, E., Solarino, S., Paul, A., Guillot, S., Schwartz, S., Dumont, T., Aubert, C., Salimbeni, S., Pondrelli, S., Wang, Q., \& Zhu, R., 2017. Earthquakes in the western Alpine mantle wedge, Gondwana Res., 44, 89-95.

Masson, F., Verdun, J., Bayer, R., \& Debeglia, N., 1999. A new gravity map of the western Alpsand its structural and tectonic consequences, Comptes Rendus l'Academie Sci. - Ser. IIa Sci. la Terre des Planetes, 329(12), 865-871.

Mathar, J. P., Ritter, J. R. R., \& Friederich, W., 2006. Surface waves image the top of the Eifel plume, Geophys. J. Int., 164(2), 377-382.

MedNet Project Partner Institutions, 1988. Mediterranean Very Broadband Seismographic Network (MedNet).

Mitterbauer, U., Behm, M., Brückl, E., Lippitsch, R., Guterch, A., Kellér, G. R., Koslovskaya, E., Rumpfhuber, E. M., \& Sumanovac, F., 2011. Shape and origin of the East-Alpine slab constrained by the ALPASS teleseismic model, Tectonophysics, 510(1-2), 195-206.

Molinari, I. \& Morelli, A., 2011. EPcrust: A reference crustal model for the European Plate, Geophys. J. Int., 185(1), 352-364.

Molinari, I., Verbeke, J., Boschi, L., Kissling, E., \& Morelli, A., 2015. Italian and Alpine threedimensional crustal structure imaged by ambient-noise surface-wave dispersion, Geochem. Geophys. Geosyst., 16(12), 4405-4421.

Montagner, J., 1994. Can seismology tell us anything about convection in the mantle?, Rev. Geoph., 32(2), 115-137.

Montagner, J. \& Jobert, N., 1988. Vectorial tomography-II. Application to the Indian Ocean, Geophys. J., 94(2), 309-344.

National Institute For Earth Physics (NIEP Romania), 1994. Romanian Seismic Network.

National Institute Of Geophysics, Geodesy, 1980. National Seismic Network of Bulgaria.

National Qbservatory Of Athens, Institute Of Geodynamics, 1997. National Observatory of Athens Seismic Network.

Nicolas, A., Hirn, A., Nicolich, R., \& Polino, R., 1990. Lithospheric wedging in the western Alps inferred from the ECORS-CROP traverse, Geology, 18(7), 587-590.

Nita, B., Maurya, S., \& Montagner, J.-P., 2016. Anisotropic tomography of the European lithospheric 
structure from surface wave studies, Geochem. Geophys. Geosyst., 17(6), 2015-2033.

Nocquet, J.-M. \& Calais, E., 2004. Geodetic measurements of crustal deformation in the Western Mediterranean and Europe, Pure Appl. Geophys., 161(3), 661-681.

OGS (Istituto Nazionale Di Oceanografia E Di Geofisica Sperimentale), 2016. North-East Italy Seismic Network.

OGS (Istituto Nazionale Di Oceanografia E Di Geofisica Sperimentale) And University Of Trieste, 2002. North-East Italy Broadband Network.

Palano, M., 2015. On the present-day crustal stress, strain-rate fields and mantle anisotropy pattern of Italy, Geophys. J. Int., 200(8), 969-985.

Panning, M. P., Lekić, V., \& Romanowicz, B. A., 2010. Importance of crustal corrections in the development of a new global model of radial anisotropy, J. Geophys. Res. Solid Earth, 115(12) $1-18$.

Passarelli, L., Roessler, D., Aladino, G., Maccaferri, F., Moretti, M., Lucente, F. P., Braun, T́., De Gori, P., Margheriti, L., Woith, H., Sebastian, H., Eleonora, R., \& Dahm, T., 2012. Pollino Seismic Experiment (2012-2014).

Passarelli, L., Govoni, A., Francesco, M., Woith, H., Strollo, A., Zieke, T., Margheriti, L., Martinelli, G., \& Dahm, T., 2017. East Pollino Experiment, Southern Italy.

Pasyanos, M. E., 2005. A variable resolution surface wave dispersion study of Eurasia, North Africa, and surrounding regions, Journal of Geophysical Research: Solid Earth 110(B12).

Paul, A. \& Nicollin, F., 1989. Thin crustal layering in Northern France: observations and modelling of the PMP spectral content, Geophysical Journal International, 99(1), 229-246.

Pilidou, S., Priestley, K., Debayle, E., \& Gudmundsson, O., 2005. Rayleigh wave tomography in the North Atlantic: high resolution images of the Iceland, Azores and Eifel mantle plumes, Lithos, 79(3-4), 453-474.

Piromallo, C. \& Morelli, A., 2003. P wave tomography of the mantle under the Alpine-Mediterranean area, J. Geophys. Res. Solid Earth, 108(B2), 1-23.

Qorbani, E., Bianchi, I., \& Bokelmann, G., 2015. Slab detachment under the Eastern Alps seen by seismic anisotropy, Earth Planet. Sci. Lett., 409, 96-108.

RESIF, 1995. RESIF-RLBP French Broad-band network, RESIF-RAP strong motion network and other seismic stations in metropolitan France.

RESIF, 2018. CEA/DASE broad-band permanent network in metropolitan France.

Rey, P., 1993. Seismic and tectono-metamorphic characters of the lower continental crust in Phanerozoic areas: A consequence of post-thickening extension, Tectonics, 12(2), 580-590.

Ritter, J. R., Jordan, M., Christensen, U. R., \& Achauer, U., 2001. A mantle plume below the Eifel volcanic fields, Germany, Earth and Planetary Science Letters, 186(1), 7-14.

Roessler, D., Passarelli, L., Govoni, A., Bautz, R., Dahm, T., Maccaferri, F., Rivalta, E., Schierjott, J., \& Woith, H., 2014. Extended Pollino Seismic Experiment, 2014-2015. 
Royal Netherlands Meteorological Institute (KNMI), 1993. Netherlands Seismic and Acoustic Network, Royal Netherlands Meteorological Institute (KNMI), Other/Seismic Network, 10.21944/e970fd34-23b9-3411-b366-e4f72877d2c5.

Royal Observatory Of Belgium, 1985. Belgian Seismic Network.

Saito, M., 1967. Excitation of free oscillations and surface waves by a point source in a vertically heterogeneous Earth, J. Geophys. Res., 72(14), 3689-3699.

Saito, M., 1988. Disper80: A subroutine package for the calculation of seismic normal-mode solutions, Seismological algorithms, pp. 293-319.

Salimbeni, S., Malusà, M. G., Zhao, L., Pondrelli, S., Margheriti, L., Paul, A., Aubert, C., Dumont, T., Schwartz, S., Pondrelli, S., Margheriti, L., Paul, A., Solarino, S., \& Aubert, C., 2018. Active and fossil mantle flows in the western Alpine region unravelled by seismic anisotropy analysis and high-resolution P wave tomography, Tectonophysics, 731-732, 35-47.

Sambridge, M., Bodin, T., Gallagher, K., \& Tkalcic, H., 2013. Transdimensional inference in the geosciences, Philos. Trans. R. Soc. A Math. Phys. Eng. Sci., 371(1984).

San Fernando Royal Naval Observatory (ROA), Universidad Complutense De Madrid (UCM), Helmholtz-Zentrum Potsdam Deutsches GeoForschungsZentrum (GFZ), Universidade De Evora (UEVORA, Portugal), \& Institute Scientifique Of RABAT (ISRABAT, Morocco), 1996. The Western Mediterranean BB seismic Network.

Schintgen, T., Förster, A., Förster, H. J., \& Norden, B., 2015. Surface heat flow and lithosphere thermal structure of the Rhenohercynian Zone in the greater Luxembourg region, Geothermics, $\mathbf{5 6}$, 93-109.

Schippkus, S., Zigone, D., Bokelmann, G., Hetényi, G. Abreu, R., Allegretti, I., Apoloner, M.-T., Aubert, C., Besançon, S., Bès De Berc, M., Bokelmann, G., Brunel, D., Capello, M., Čarman, M., Cavaliere, A., Chèze, J., Chiarabba, C., Clinton, J., Cougoulat, G., Crawford, W. C., Cristiano, L., Czifra, T., D'alema, E., Danesi, S., Daniel, R., Dannowski, A., Dasović, I., Deschamps, A., Dessa, J.-X., Doubre, C., Egdorf, S., Fiket, T, Fischer, K., Friederich, W., Fuchs, F., Funke, S., Giardini, D., Govoni, A., Gráczer, Z., Gröschl, G., Heimers, S., Heit, B., Herak, D., Herak, M., Huber, J., Jarić, D., Jedlička, P., Jia, X Jund, H., Kissling, E., Klingen, S., Klotz, B., Kolínský, P., Kopp, H., Korn, M., Kotek, J., Kühne, L.) Kuk, K., Lange, D., Loos, J., Lovati, S., Malengros, D., Margheriti, L., Maron, C., Martin, X., Massa, M., Mazzarini, F., Meier, T., Métral, L., Molinari, I., Moretti, M., Munzarová, H., Nardi, A., Pahor, J., Paul, A., Péquegnat, C., Petersen, D., Pesaresi, D., Piccinini, D., Piromałlo, C. Plenefisch, T., Plomerová, J., Pondrelli, S., Prevolnik, S., Racine, R., Régnier, M., Reiss, M., Ritter, J., Rümpker, G., Salimbeni, S., Santulin, M., Scherer, W., Schippkus, S., SchulteKortnack, D., Šipka, V., Solarino, S., Spallarossa, D., Spieker, K., Stipčević, J., Strollo, A., Süle, B., Szanyi, G., Szücs, E., Thomas, C., Thorwart, M., Tilmann, F., Ueding, S., Vallocchia, M., Vecsey, L., Voigt, R., Wassermann, J., Wéber, Z., Weidle, C., Wesztergom, V., Weyland, G., Wiemer, S., Wolf, F., Wolyniec, D., Zieke, T., \& Živčić, M., 2020. Azimuthal anisotropy in the wider Vienna 
basin region: a proxy for the present-day stress field and deformation, Geophys. J. Int., 220(3), 2056-2067.

Schivardi, R. \& Morelli, A., 2011. EPmantle: A 3-D transversely isotropic model of the upper mantle under the European Plate, Geophys. J. Int., 185(1), 469-484.

Scripps Institution Of Oceanography, 1986. IRIS/IDA Seismic Network.

Sector For Seismology, Institute Of Hydrometeorology, 1982. Montenegrin Seismic Network.

Segou, M., McCloskey, J., Baptie, B., \& Hawthorn, D., 2016. Armatrice Sequence International.

Seiberlich, C., Ritter, J. R., \& Wawerzinek, B., 2013. Topography of the lithosphere-asthenosphere boundary below the Upper Rhine Graben Rift and the volcanic Eifel region, Central Europe, Tectonophysics, 603, 222-236.

Sens-Schönfelder, C. \& Delatre, M., 2011. Ketzin Seismic Monitoring Network.

Shapiro, N. \& Campillo, M., 2004. Emergence of broadband Rayleigh waves from correlations of the ambient seismic noise, Geophys. Res. Lett., 31(7), n/a-n/a.

Shapiro, N. M., Campillo, M., Stehly, L., \& Ritzwoller, M. H., 2005. High-resolution surface-wave tomography from ambient seismic noise, Science (80-. )., 307(5715), 1615-1618.

Sieminski, A., Debayle, E., \& Lévêque, J. J., 2003. Seismic evidence for deep Tow-velocity anomalies in the transition zone beneath West Antarctica, Earth Planet. Sci. Lett., 216(4), 645-661.

Singh, S. C. \& McKenzie, D., 1993. Layering in the lower crust, Geophysical Journal International, 113(3), 622-628.

Slovenian Environment Agency, 2001. Seismic Network of the Republic of Slovenia.

Smith, M. \& Dahlen, F., 1973. The Azimuthal Dependence of Love and Rayleigh Wave Propagation in a Slightly Anisotropic Medium fr ) of the angula $\bullet$ r frequency o $\bullet$ ( k ) and, J. Geophys. Res., $78(17)$.

SNSN, 1904. Swedish National Seismic Network.

Solarino, S., Malusà, M. G., Eva, E., Guillot, S., Paul, A., Schwartz, S., Zhao, L., Aubert, C., Dumont, T., Pondrelli, S., Salimbeni, S., Wang, Q., Xu, X., Zheng, T., \& Zhu, R., 2018. Mantle wedge exhumation beneath the Dora-Maira (U)HP dome unravelled by local earthquake tomography (Western Alps), LITHOS, 296-299, 623-636.

Spada, M., Bianchi, I., Kissling, E., Agostinetti, N. P., \& Wiemer, S., 2013. Combining controlledsource seismology and receiver function information to derive 3-D Moho topography for Italy, Geophys. J. Int., 194(2), 1050-1068.

Spakman, W. \& Wortel, R., 2004. A Tomographic View on Western Mediterranean Geodynamics, pp. 31-52, Springer Berlin Heidelberg.

Spakman, W., van der Lee, S., \& van der Hilst, R., 1993. Travel-time tomography of the EuropeanMediterranean mantle down to $1400 \mathrm{~km}$, Physics of the Earth and Planetary Interiors, 79(1-2), 3-74.

Stehly, L., Campillo, M., \& Shapiro, N. M., 2006. A study of the seismic noise from its long-range 
correlation properties, J. Geophys. Res. Solid Earth, 111(10).

Stehly, L., Fry, B., Campillo, M., Shapiro, N. M., Guilbert, J., Boschi, L., \& Giardini, D., 2009. Tomography of the Alpine region from observations of seismic ambient noise, Geophys. J. Int., 178, 338-350.

Swiss Seismological Service (SED) At ETH Zurich, 1983. National Seismic Networks of Switzerland. Takeuchi, H. \& Saito, M., 1972. Seismic surface waves, Methods in computational physics, 11, 217295.

Tarantola, A. \& Valette, B., 1982. Generalized nonlinear inverse problems solved using the least squares criterion, Rev. Geophys., 20(2), 219-232.

Technological Educational Institute Of Crete, 2006. Seismological Network of Crete.

Thybo, H., Balling, N., Maupin, V., Ritter, J., \& Tilmann, F., 2012. ScanArray Core (1G 2012-2017)

Tkalčić, H., Pasyanos, M. E., Rodgers, A. J., Gök, R., Walter, W. R., \& Al-Amri, A., 2006. A multistep approach for joint modeling of surface wave dispersion and teleseismic receiver functions: Implications for lithospheric structure of the Arabian Peninsula, J. Geophys. Res., 111(B11), 1-25, B11311.

Trampert, J. \& Woodhouse, J., 2003. Global anisotropic phase velocity maps for fundamental mode surface waves between 40 and 150s., Geophys. J. Int., 154(1), 154-165.

University Of Athens, 2008. University of Athens, Seismological Laboratory,

University Of Bari "Aldo Moro", 2013. OTRIONS, Seismic networks of Gargano Area (Italy).

University Of Genova, 1967. Regional Seismic Network of North Western Italy.

University Of Patras, Geology Department, 2000. PSLNET, permanent seismic network operated by the University of Patras, Greece.

University Of Trieste, 1993. Friuli Venezia Giulia Accelerometric Network.

University Of Zagreb, 2001. Croatian Seismograph Nétwork.

Verbeke, J., Boschi, L., Stehly, L., Kissling, E., \& Michelini, A., 2012. High-resolution Rayleigh-wave velocity maps of central Europe from a dense ambient-noise data set, Geophys. J. Int., 188(3), $1173-1187$.

Vignaroli, G., Faccenna, C., Jolivet, L., Piromallo, C., \& Rossetti, F., 2008. Subduction polarity reversal at the junction between the Western Alps and the Northern Apennines, Italy, Tectonophysics, 450(1-4), 34-50.

Weidle, C. \& Maupin, V., 2008. An upper-mantle S-wave velocity model for Northern Europe from Love and Rayleigh group velocities, Geophysical Journal International, 175(3), 1154-1168.

Wortel, M. J. R. \& Spakman, W., 2000. Subduction and Slab Detachment in the MediterraneanCarpathian Region, Science, 290(5498), 1910-1917.

Yang, Y, Ritzwoller, M. H., Levshin, A. L., \& Shapiro, N. M., 2007. Ambient noise Rayleigh wave tomography across Europe, Geophys. J. Int., 168(1), 259-274.

Yuan, H. \& Bodin, T., 2018. A Probabilistic Shear Wave Velocity Model of the Crust in the Central 
West Australian Craton Constrained by Transdimensional Inversion of Ambient Noise Dispersion, Tectonics, 37(7), 1994-2012.

Yuan, H. \& Romanowicz, B., 2010. Lithospheric layering in the North American craton, Nature, 466(7310), 1063-1068.

ZAMG-Zentralanstalt Für Meterologie Und Geodynamik, 1987. Austrian Seismic Network.

Zhao, L., Paul, A., Guillot, S., Solarino, S., Malusà, M. G., Zheng, T., Aubert, C., Salimbeni, S., Dumont, T., Schwartz, S., Zhu, R., \& Wang, Q., 2015. First seismic evidence for continental subduction beneath the Western Alps, Geology, 43(9), 815-818.

Zhao, L., Paul, A., Malusà, M. G., Xu, X., Zheng, T., Solarino, S., Guillot, S., Schwartz, S., Dumont, T., Salimbeni, S., Aubert, C., Pondrelli, S., Wang, Q., \& Zhu, R., 2016a. Continuity of the Alpine slab unraveled by high-resolution P wave tomography, J. Geophys. Res. Solid Earth, 121(12), 8720 8737.

Zhao, L., Paul, A., Solarino, S., \& RESIF, 2016b. Seismic network YP: CIFALPS temporary experiment (China-Italy-France Alps seismic transect).

Zhao, L., Malusà, M. G., Yuan, H., Paul, A., Guillot, S., Lu, Y., Stehly, L., Solarino, S., Eva, E., Lu, G., et al., 2020. Evidence for a serpentinized plate interface favouring continental subduction, Nature Communications, 11(1), 2171.

Zhu, H., Bozdă̆, E., Peter, D., \& Tromp, J., 2012. Structure of the European upper mantle revealed by adjoint tomography, Nature Geoscience, 5(7), 493-498.

Zhu, H., Bozdăg, E., \& Tromp, J., 2015. Seismic structure of the European upper mantle based on adjoint tomography, Geophys. J. Int., 201(1), 18-52. 


\section{APPENDIX}

\section{APPENDIX A: RAY DENSITY}

$8 \mathrm{~s}$

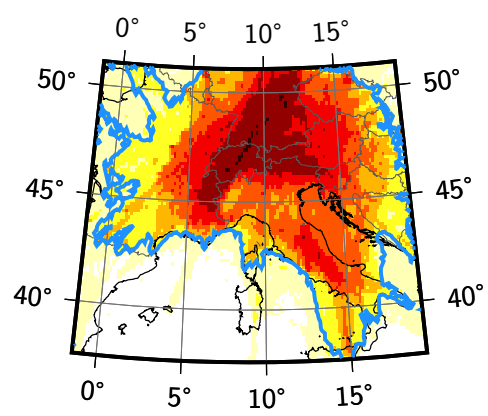

$30 \mathrm{~s}$
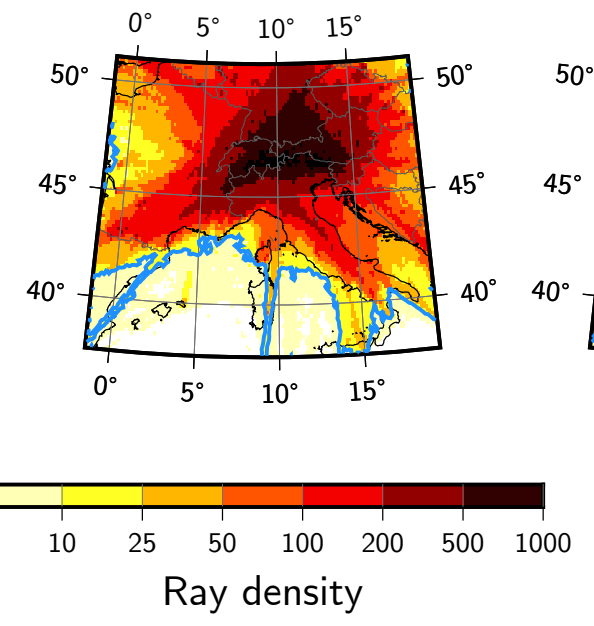

$55 \mathrm{~s}$

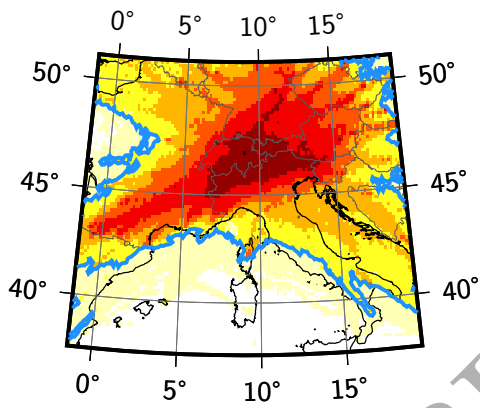

Figure A.1: Ray density maps at periods $8 \mathrm{~s}, 30 \mathrm{~s}$ and $55 \mathrm{~s}$ showing the number of paths crossing each $0.15^{\circ} \times 0.15^{\circ}$ cell. The blue line delimits the area with ray density higher than 10. 


\section{APPENDIX B: FLAT TESTS}

To assess the lateral resolution of the 2-D group velocity maps, we used flat tests where we estimate how a known and uniform perturbation of velocity is recovered by the regionalization method (i.e. 2-D tomography) of Debayle \& Sambridge (2004) given our data coverage, choices of parameterization and regularization. For each period, we compute synthetic group velocities between receivers of every station pair in the dataset assuming, at each grid point, a velocity perturbation of $15 \%$ in amplitude with respect to the reference velocity calculated as the mean of the real data. The 2-D tomography is then performed with the same parameters used in the data inversion and discussed in Section 3.1. Well resolved areas are the ones where the recovered perturbation is close to the one we introduced.

Figure B.1 shows the results of flat tests performed for six periods between 8 and $90 \mathrm{~s}$, including periods 8,30 and $55 \mathrm{~s}$ discussed in the text. From those tests, we show that our data coverage and chosen parameterization and regularization enable us to recover more than $90 \%$ of the amplitude of the initial perturbation for periods as long as $80 \mathrm{~s}$ in the Alps and Northern Italy. In the same period range, at least $30 \%$ of the input velocity anomaly is recovered in most of Europe, except in the Mediterranean sea. At longer periods, we lose resolution in Italy. In addition, some smearing is observed in the SW-NE direction, in Southern France, from period $55 \mathrm{~s}$.

Finally, these results show that the smoothing parameters, i.e. the correlation lengths, are adapted to the data coverage at every period since no velocity oscillation is observed around the ray paths. 
$8 \mathrm{~s}$

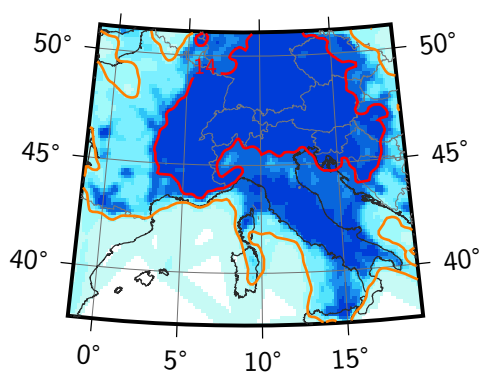

$55 \mathrm{~s}$

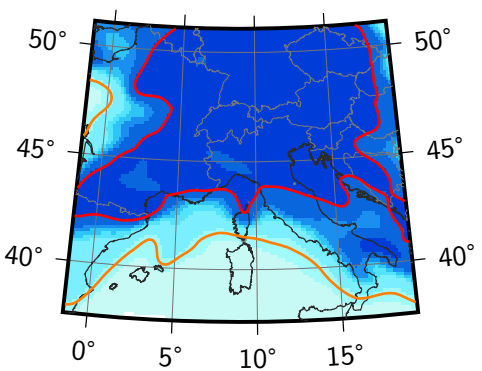

$20 \mathrm{~s}$

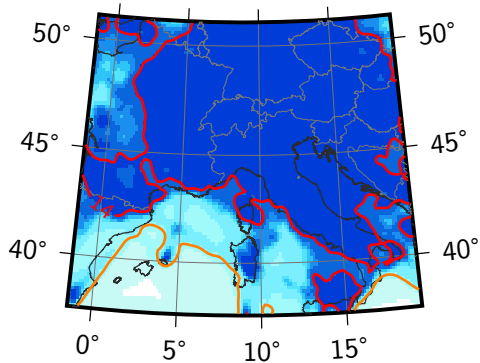

$80 \mathrm{~s}$
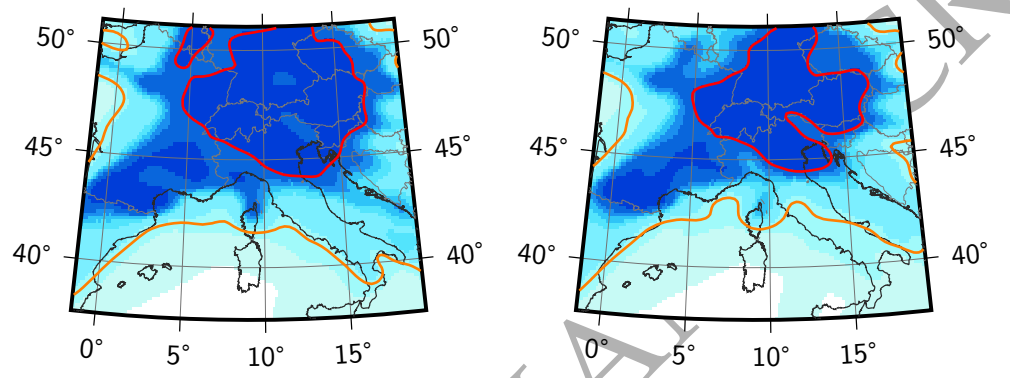

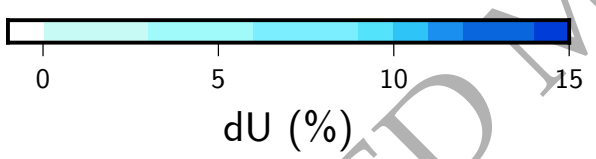

Figure B.1: Results of flat tests. The input anomaly represents a velocity perturbation of $15 \%$ at each grid point, i.e. a flat model. The recovered perturbations after regionalization are shown for periods $8,20,30,55,80$ and $90 \mathrm{~s}$. Red lines represent a velocity anomaly of $14 \%$, i.e. $90 \%$ of the input perturbatiøn. Orange lines represent an anomaly of $5 \%$, i.e. $30 \%$ of the input model. 
APPENDIX C: ADDITIONAL GROUP VELOCITY MAPS 
Rayleigh

0

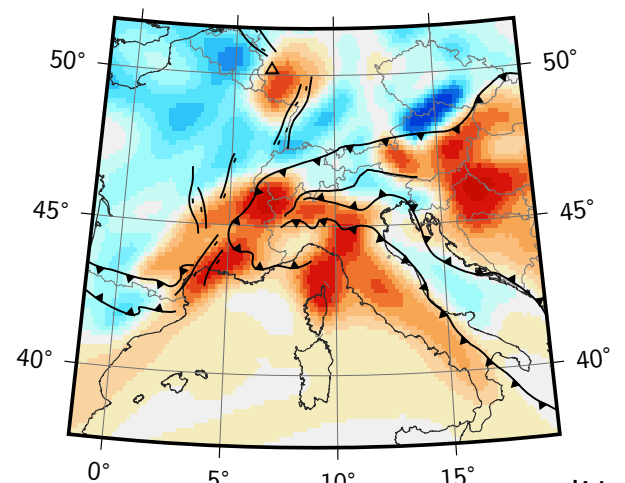

Love

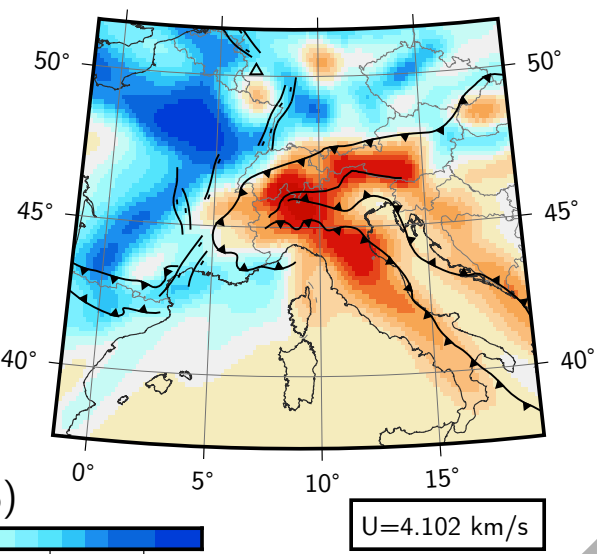

2

$\begin{array}{lllll}-4 & -2 & 0 & 2 & 4\end{array}$

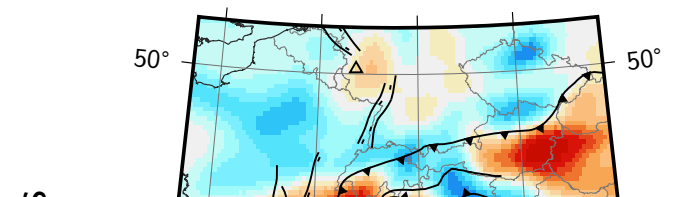

$\infty$

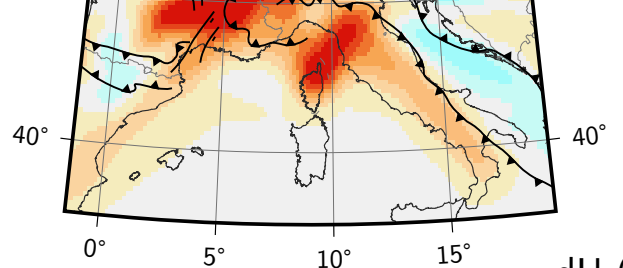

$\mathrm{U}=3.776 \mathrm{~km} / \mathrm{s}$

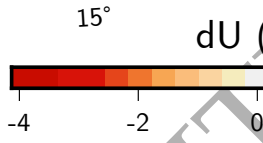

$U(\%)$

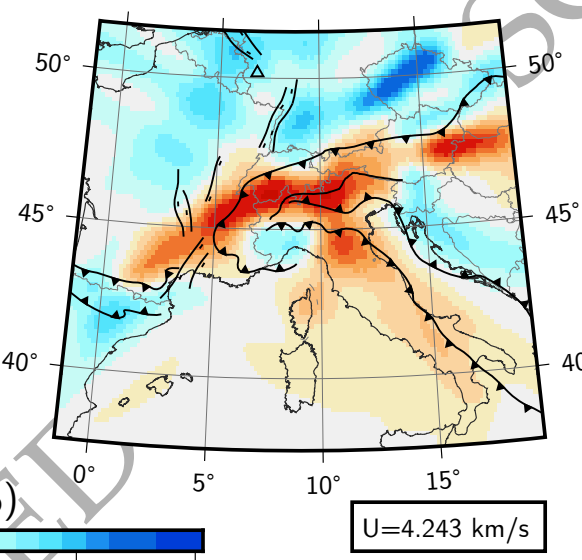

n
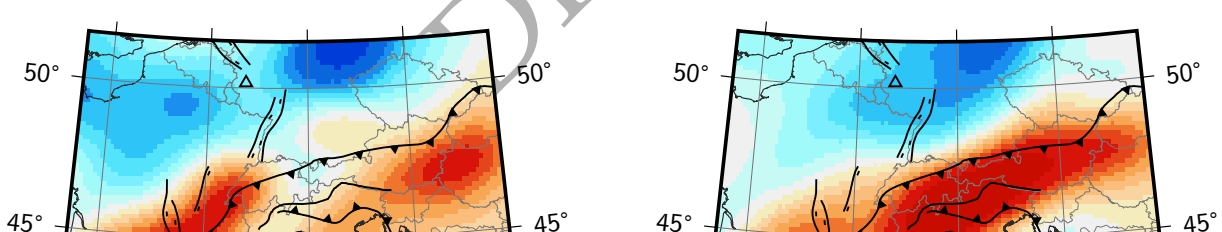

$-45^{\circ}-45^{\circ}$

$40^{\circ}$

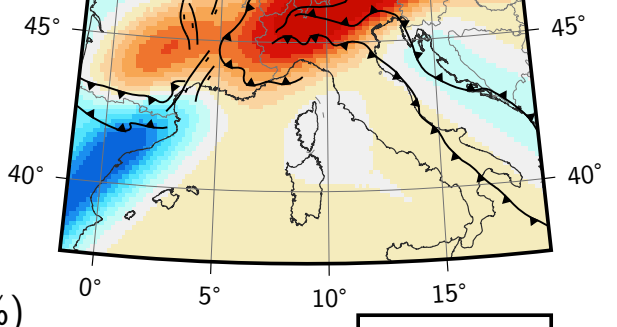

$\mathrm{U}=4.326 \mathrm{~km} / \mathrm{s}$

Figure C.1. Group velocity perturbation maps for Rayleigh and Love waves at periods 60,80 and $110 \mathrm{~s}$. The reference group velocity $U$ is indicated below each map. 


\section{APPENDIX D: DATA FIT}

Our solution model is not a single velocity field but instead a probability distribution in the model space, and computing a single data misfit value is not possible. We decide to compare observations to the data vector obtained after averaging over the ensemble of data estimated for the ensemble of models in the solution. We compute separately the fit to Love and Rayleigh data at each period between 5 and $149 \mathrm{~s}$, with an increment of $5 \mathrm{~s}$.

For each geographical point, the misfit between observed data, and data obtained from the probabilistic solution is given by:

$$
\begin{gathered}
\Phi_{R}(T)=\frac{\sqrt{\left(u_{R}(T, \mathbf{m})-U_{R}(T)\right)^{2}}}{U_{R}(T)} \\
\Phi_{L}(T)=\frac{\sqrt{\left(u_{L}(T, \mathbf{m})-U_{L}(T)\right)^{2}}}{U_{L}(T)}
\end{gathered}
$$

where, for Rayleigh and Love waves respectively, $\Phi_{R}(T, \mathbf{m})$ and $\Phi_{L}(T, \mathbf{m})$ are the mean of the estimated group velocities at period $T$ from each model of the posterior distribution. $U_{R}(T)$ and $U_{L}(T)$ are the velocities extracted at $T$ from the Rayleigh and Love 2-D velocity maps. Misfit maps are shown in Figure D.1 for periods 10, 30 and $55 \mathrm{~s}$. The misfit is the highest at short periods (10 s on the maps), in thick sedimentary basins such as the Po plain or the Vienna basin, and could be related to the complex structure of the basins not perfectly retrieved in our models. 
Data misfit Rayleigh
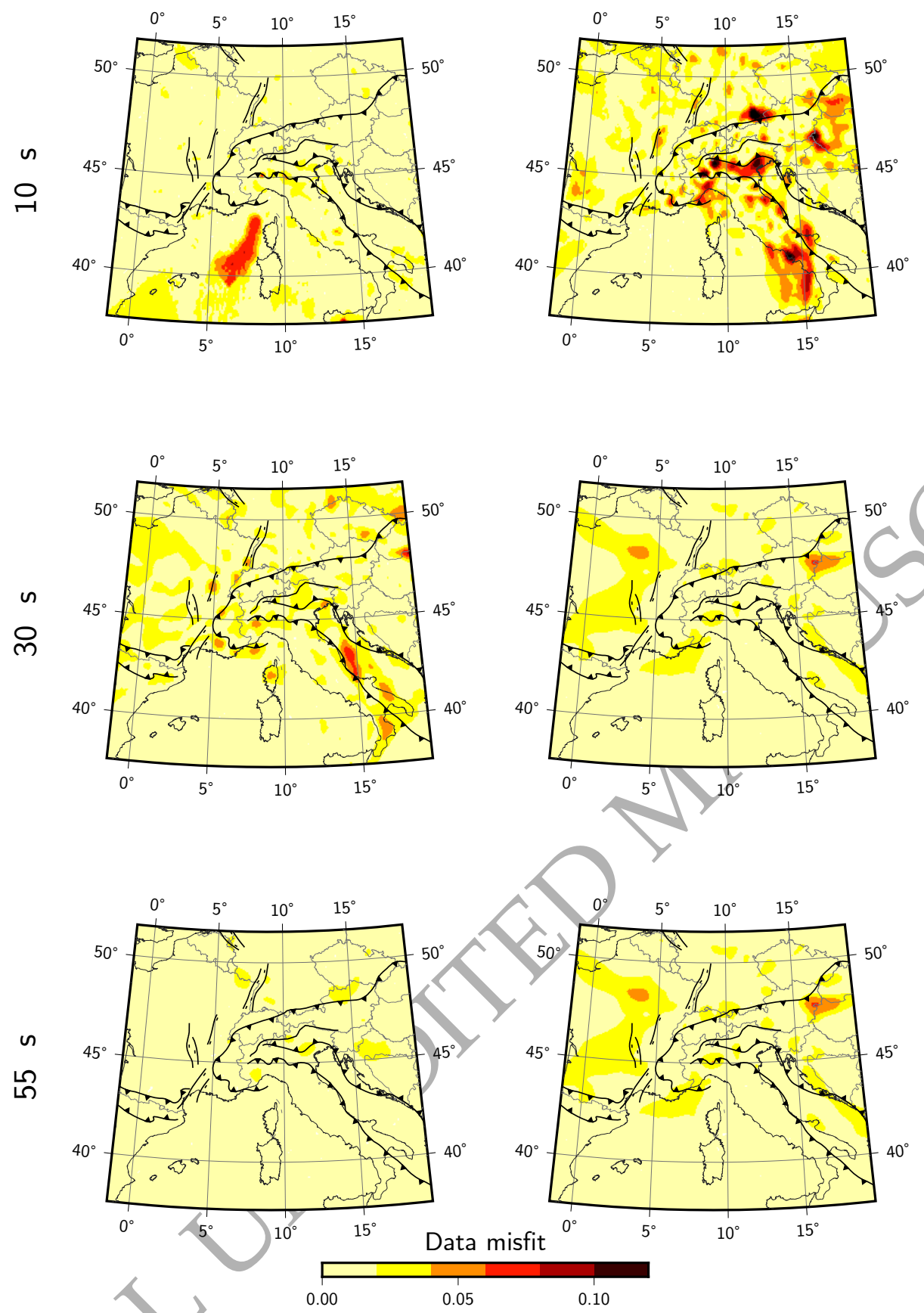

Figure D.1. Bata misfit for Rayleigh and Love waves at 10, 30 and $55 \mathrm{~s}$, as defined in Eq. D.2.

\section{APPENDIX E: DATA ORIGIN}

Seismic ambient noise data used in this study were collected from networks with codes 1G: Thybo et al. (2012); 2D; 4A: Passarelli et al. (2012); 4C; 6E; 6G: Sens-Schönfelder \& Delatre (2011); 6H; 8A: Dias et al. (2010); 8X; 9C: Heit et al. (2010); AC: Institute Of Geosciences, 
Energy, Water And Environment (2002); BA; BE: Royal Observatory Of Belgium (1985); BN; BS: National Institute Of Geophysics, Geodesy (1980); BW: Department Of Earth And Environmental Sciences, Geophysical Observatory, University Of Munchen (2001); C4; CA: Institut Cartogràfic I Geològic De Catalunya (1984); CH: Swiss Seismological Service (SED) At ETH Zurich (1983); CL: Corinth Rift Laboratory Team And RESIF Datacenter (2013); CQ: Geological Survey Department Cyprus (2013); CR: University Of Zagreb (2001); CZ: Institute Of Geophysics (1973); DK; DZ; EB; EE; EI: INSN (1993); ES: Instituto Geografico Nacional, Spain (1999); FN; FR: RESIF (1995); G : Institut De Physique Du Globe De Paris (IPGP) \& (EOST); GB; GE: GEOFON Data Centre (1993); GR: Federal Institute for Geosciences and Natural Resources (BGR) (1976); GU: University Of Genova (1967); HA: University Of Athens (2008); HC: Technological Educational Institute Of Crete (2006); HE: Institute Of Seismology, University Of Helsinki (1980); HF; HL: National Observatory Of Athens, Institute Of Geodynamics (1997); HP: University Of Patras, Geology Department (2000); HT: Aristotle University Of Thessaloniki Seismological Network (1981); HU: Kövesligethy Radó Seismological Observatory (Geodetic And Geophysical Institute, Research Centre For Astronomy And Earth Sciences, Hungarian Academy Of Sciences (MTA CSFK GGI KRSZO)) (1992); IB: Institute Earth Sciences "Jaume Almera" CSIC (ICTJA Spain) (2007); II: Scripps Institution Of Oceanography (1986); IM; IP; IS; IU: Albuquerque Seismological Laboratory (ASL)/USGS (1988); IV: INGV Seismological Data Centre (1997), IX; KO: Bogazici University Kandilli Observatory And Earthquake Research Institute (2001), LC: Laboratorio Subterraneo De Canfranc (2011); LX: Instituto Dom Luiz (IDL)-Faculdade De Ciências Da Universidade De Lisboa (2003); MD: Geological And Seismological Institute Of Moldova (2007); ME: Sector For Seismology, Institute Of Hydrometeorology (1982); MN: MedNet Project Partner Institutions (1988); MT: French Landslide Observatory - Seismological Datacenter / RESIF (2006); NI: OGS (Istituto Nazionale Di Oceanografia E Di Geofisica Sperimentale) And University Of Trieste (2002); NL: Royal Netherlands Meteorological Institute (KNMI) (1993); NO; NS; OE: ZAMG-Zentralanstalt Für Meterologie Und Geodynamik (1987); OT: University Of Bari "Aldo Moro" (2013); OX: OGS (Istituto Nazionale Di Oceanografia E Di Geofisica Sperimentale) (2016); PL; PM. Instituto Português Do Mar E Da Atmosfera, I.P. (2006); RD: RESIF (2018); RF: University Of Trieste (1993); RO: National Institute For Earth Physics (NIEP Romania) (1994); SI; SJ; SK: Earth Science Institute Of The Slovak Academy Of Sciences (ESISAS) (2004); SL: Slovenian Environment Agency (2001); SS; ST: Geological Survey-Provincia Autonoma Di Trento (1981); SX: Leipzig University (2001); TH: Jena, Friedrich Schiller Uniyérsity (2009); TT; TU: Disaster And Emergency Management Presidency (AFAD Turkey) 
(1990); TV; UK; UP: SNSN (1904); WM: San Fernando Royal Naval Observatory (ROA) et al. (1996); X7: Chevrot et al. (2017); XT: AlpArray Seismic Network (2014); Y4: Roessler et al. (2014); Y7; YF; YH: DANA (2012); YI: Chaljub (2017); YP: Zhao et al. (2016b); YR: Segou et al. (2016); YW: Guéguen et al. (2017); YZ: Passarelli et al. (2017); Z3: AlpArray Seismic Network (2015); ZH: Deschamps \& Beucler (2013); ZS: Heit et al. (2017); ZU: Chevrot et al. (2018); ZW. 